\title{
Insights into smallholder capacity for agricultural commercialisation: Evidence from four African contexts
}

\author{
Amrita Saha ${ }^{1}$ D $\cdot$ Rachel Sabates-Wheeler ${ }^{1} \cdot$ John Thompson $^{1}$
}

Accepted: 17 May 2021 / Published online: 13 July 2021

(c) The Author(s) 2021

\begin{abstract}
Over the last 15 years, the agricultural economics and development literature has amply highlighted success stories of smallholder farmers in developing countries, illustrating their increased engagement and integration with markets, in other words, higher rates of commercialisation. Yet, this seeming 'success' should not detract from the large proportion of farmers who, through engaging in high-value market chains, face high risks that often limit the extent of their engagement. This study, across four African contexts in Ghana, Tanzania, Nigeria and Zimbabwe, strives to better understand smallholder participation in agricultural commercialisation. Using new detailed cross-sectional household-level data, from the Agricultural Policy Research in Africa (APRA) consortium, collected over 2017-2018, we analyse assets as a determining factor for localised patterns smallholder commercialisation. Applying asset-based thresholds, we capture commercialisation 'capacity' —an indicator of the household's commercialisation potential and ability to respond to risks. Despite the possibility to increase commercialisation as well as institutional arrangements that may reduce risk, such as contract farming, benefits from linkages with medium-scale farmers or returns from specific crop types, we find that households may yet be constrained by lower capacity. Hence, the need for targeted support for those at the margins and with limited assets; with the most pronounced and significant constraints for lower capacity households in study areas in Tanzania. These results can better inform development policies for agriculture where it is important to be able to specifically target households rather than a one size fits all approach.
\end{abstract}

Keywords Commercialisation $\cdot$ Smallholders $\cdot$ Capacity

Amrita Saha

A.Saha@ids.ac.uk

Rachel Sabates-Wheeler

R.Sabates-Wheeler@ids.ac.uk

John Thompson

J.Thompson@ids.ac.uk

1 Institute of Development Studies (IDS), University of Sussex, Brighton, UK 


\section{Résumé}

Au cours des 15 dernières années, la littérature sur l'économie et le développement agricoles a largement mis en avant les réussites des petits producteurs agricoles dans les pays en développement, illustrant leur engagement et leur intégration accrus aux marchés, ou en d'autres termes, des taux de commercialisation plus élevés. Pourtant, cet apparent « succès » ne devrait pas occulter la grande proportion d'agriculteurs qui, en s'engageant dans la chaîne de valeur des marchés à forte valeur ajoutée, sont confrontés à des risques élevés qui limitent souvent l'étendue de leur engagement. Cette étude, menée dans quatre contextes africains au Ghana, en Tanzanie, au Nigeria et au Zimbabwe, s'attache à mieux comprendre la participation des petits producteurs à la commercialisation agricole. À l'aide de nouvelles données transversales détaillées au niveau des ménages, collectées sur la période 2017-2018 par le Consortium de recherche sur les politiques agricoles en Afrique (APRA), nous analysons les actifs en tant que facteur déterminant pour des modèles localisés de commercialisation par les petits producteurs. Grâce à l'applicatin de seuils basés sur les actifs, nous mesurons la « capacité » de commercialisation - un indicateur du potentiel de commercialisation du ménage et de sa capacité à répondre aux risques. En dépit de la possibilité d'accrôtre la commercialisation et malgré les dispositions institutionnelles permettant de réduire les risques, comme l'agriculture contractuelle, les bienfaits apportés par les liens créés avec des agriculteurs de taille moyenne ou les revenus issus de cultures spécifiques, nous constatons que les ménages peuvent encore être limités par une capacité moindre. Il est donc nécessaire d'accompagner de façon différenciée les producteurs en marge du marché qui disposent d'actifs limités ; en sachant que les ménages qui ont la capacité la moins importante sont ceux qui font face aux contraintes les plus prononcées et aux obstacles les plus importants dans les zones de l'étude en Tanzanie. Ces résultats permettent de mieux éclairer les politiques de développement de l'agriculture, qui doivent impérativement pouvoir cibler spécifiquement les ménages avec une approche différenciée plutôt qu'une approche unique.

\section{Introduction}

Commercialisation of smallholder agriculture can lead to improved productivity, improved incomes, employment growth and poverty reduction (Barrett 2008; Carletto et al. 2017; Muricho et al. 2017; Muriithi and Matz 2015; Tipraqsa and Schreinemachers 2009; Von Braun and Kennedy 1994). Yet, smallholder farm households that are commercialising face risks due to the relatively high costs of investments needed in inputs, labour and machinery and in accessing different markets for sales and processing, among other factors. These hurdles can lead to a worsening of their situation in the short-term. While some smallholders will be better able to respond to such risks and continue to commercialise, others may fall back into subsistence. The likely pathways will depend critically on household asset ownership, especially with imperfect functioning of agricultural factor markets (Dillon and Barrett 2014; Carter and Barrett 2006; Sadoulet and de Janvry 1995; Dorward et al. 2009; Dorward, 2009; Josphat and Scoones 2012). 
To better understand smallholder participation in agricultural commercialisation, we conceptualise smallholder 'capacity' to respond to risks from commercialisation using the logic that household commercialisation will be experienced differently depending on current asset ownership. ${ }^{1}$ Households with larger asset holdings are usually better placed to take advantage of commercialisation opportunities (Cazzuffi et al. 2020; Hernández et al. 2007). Assets reflect accumulated past wealth, current available resources, as well as security in the future, and will therefore play a vital role in households' responses to commercialisation and the associated risks (Davis and Baulch 2011; Zezza et al. 2011). Assets serve as long-term welfare measures, are less likely to fluctuate in value than incomes over short periods, and can make a direct contribution to household productivity. In fact, research suggests that households, who in the previous period were selling a bigger share of their agricultural output, are likely to have higher current assets levels (Cazzuffi et al. 2020; Michelson 2013; Muriithi and Matz 2015).

\section{Smallholders' Capacity for Commercialisation}

The rate at which smallholders commercialise will depend on retaining a minimum level of assets to weather the likely risks from commercialisation. In fact, there will be thresholds below which (and in the absence of external support) the most asset poor are 'stuck' and unable to commercialise without facing higher risk and possibly worse situations, and above which better off farmers are able to reap the benefits from high levels of commercialisation at relatively low risk to their lives and livelihoods. We capture capacity of the smallholder household as relative to the threshold asset levels required to support the household above the income poverty line. ${ }^{2}$ This implies that capacity will determine a household's potential for further commercialisation, with some households realising this potential but others not.

Using observed current income poverty thresholds, we determine a unique asset poverty threshold by mapping asset ownership corresponding to the income poverty. We define households that are above the asset poverty threshold as 'Higher Capacity' (HC) and those that are below as 'Lower Capacity' (LC). These levels reveal the household's potential for commercialisation-given the household's current capacity, smallholders follow certain routes that may then lead to higher or lower commercialisation that will be known with time. In our application we make use of current asset levels to identify the asset poverty thresholds, assuming that commercialisation capacity of a household in any one period will depend on asset levels required to maintain the household

\footnotetext{
${ }^{1}$ We draw inspiration from ideas related to the concept of vulnerability in economics that refers to a probabilistic ex-ante measure of the likelihood that future values will fall below a certain threshold (Calvo and Dercon 2013; Chaudhuri et al. 2002; Ligon and Schechter 2003; Christiaensen and Subbarao 2005). However, we do not model vulnerability directly.

2 Applying an adapted approach of Phadera et al. (2019), and building on ideas from Chaudhuri et al. (2002), which has been widely applied, as in Chaudhuri 2003; Christiaensen and Subbarao 2005; Günther and Harrtgen 2009; among others.
} 
above the income poverty line. ${ }^{3}$ The idea that risks can be mediated by an identifiable set of capacities found in households is not new. However, our concept of capacity for commercialisation in a given period is new, deriving from existing work to model asset thresholds to identify such capacity for agriculture commercialisation.

Further, there may be risk-reduction options for commercial crops, and three are of relevance to this study. First, contract-farming, with growers and buyers in agreements about the production of specific agricultural commodities, has shown positive income effects for growers in certain settings (Rao and Qaim 2011; Bellemare 2012; Tripathi et al. 2005). Second, smallholder linkages with medium-scale farmers may also provide support, such as through changes in the structure and performance of commodity markets that improve nearby smallholders' access to buyers and services (Burke et al. 2020). Finally, the types and combination of crops grown, among food and non-food/industrial crops, are also important determinants of commercialisation as sale of non-food cash crops can be impeded by risks and costs in the food marketing system (Govereh and Jayne 2003).

\section{Four different commercialisation contexts}

To examine capacity and risk-reduction factors, our study focuses on smallholder capacity across four specific local contexts in Ghana, Tanzania, Nigeria and Zimbabwe. Each context is different, so we draw narratives independently for each study setting.

- In Ghana, we study smallholders (contract and non-contract) in the oil palm belt of South-Western Ghana, where labour constraints on plantations and lack of access to credit and agricultural inputs have been major hurdles to commercialisation (Rhebergen et al. 2020).

- In Tanzania, our analysis focuses on farmer groups that are applying the System of Rice Intensification (SRI) ${ }^{4}$ in Kilombero Plantation Limited (KPL) — a largescale rice farm in Mngeta division of the Morogoro region, where farmers have reported increasing yields, but also complained about the costs and risks from crop failure (West and Haug 2017).

- Our Nigerian sample of smallholders are situated in Kaduna and Ogun state, growing maize, cassava and sorghum, and are located in close vicinity of medium-scale farmers, where investment in assets and durables has been found as a potentially important driver of agricultural commercialisation (Muyanga et al. 2019).

\footnotetext{
${ }^{3}$ Predicting future asset ownership ideally requires panel data (which we do not currently have), or very strong assumptions when estimating the household's vulnerability level i.e. the probability that a household with certain characteristics will be poor, with cross-sectional data, such as variability across households can proxy variability in household assets over time (Appiah-Kubi et al. 2008; Azam and Imai 2009, Jamal 2009). The expected (mean) value of assets, and, the volatility of asset values have been used to estimate the probability that future asset ownership will be below a certain threshold (Chaudhuri and Datt 2001; Chaudhuri et al. 2002; Chaudhuri 2003; Pritchett et al. 2000). Recently, Cissé and Barrett (2018) and Phadera et al. (2019) apply this framework which describes asset poverty thresholds at different points in time, drawing on Barrett and Constas (2014: 14,625); and, Phadera et al. (2019) provide a method to create an asset based threshold at one point in time.

${ }^{4}$ An approach which uses less water and requires less farm inputs than conventional rice growing practices.
} 
- Finally, the Zimbabwean smallholders grow tobacco and maize in Mvurwi and the Concession areas of Mazowe District, where those able to afford inputs, gain access to contracts and also grow sufficient maize to cover food needs can profit significantly from growing tobacco (Scoones et al. 2018).

By utilising rich context-specific data, we are able to draw insights on more localised patterns of commercialisation and capacity, which is otherwise a limitation of working with nationally representative Living Standards Measurement Study (LSMS) datasets. Our aim is therefore to present evidence on commercialisation that highlights aspects that are most meaningful to the local population at a micro-economic level that can vary widely, depending on the respective schemes and agricultural policies in place (Bachewe et al. 2018; Birner and Resnick 2010; Pingali and Rosegrant 1995; Matthys et al. 2021).

Methodologically, we adapt an asset thresholds approach, also used most recently in Phadera et al. (2019), and inspired by earlier ideas in Chaudhuri et al. (2002); Cissé and Barrett (2018); Cahyadi and Waibel (2016). We adopt a forward-looking approach (Ward 2016) $)^{5}$ using the first round of a panel dataset, where identifying the households with lower capacities today, and hence those more vulnerable, can help inform the path for localised development interventions that aim to address capacity gaps for smallholders. In the future, using the second round of the panel we will be able to observe whether this capacity is then realised.

We find that commercialisation is constrained by lower capacity, highlighting the need for targeted support for those at the margins and with limited assets; with the most pronounced and significant constraints for lower capacity households in Tanzania. The remainder of this article is organised as follows. "Methods" section presents the methods, including details of data collection, measurement of key variables and the empirical strategy. "Results" section presents the results-descriptive analysis of key variables, estimation of capacities for agricultural commercialisation, and including possible limitations that can be overcome in future work. Finally, "Conclusions and policy implications" section concludes with a discussion of the implications of this research for smallholders commercialisation.

\section{Methods}

The data for this study are derived from household surveys conducted in 2017-2018 by the Agricultural Policy Research in Africa (APRA) consortium. Household surveys were conducted in Ghana, Nigeria, Tanzania and Zimbabwe, each comprising representative data for highly commercialised areas in specific parts of these countries. A total of 3993 farm households were interviewed. For the purpose of this

\footnotetext{
5 Ward (2016) among others have argued for strong justification for development and other povertyreduction strategies to be more forward looking and consider what their impacts or outcomes might be in the future.
} 
paper, we focus on the smallholders sub-sample only-a dataset of 2394 (60\% of our overall sample) smallholder farm households (using one consistent definition of total land area cultivated of less than or equal to 5 hectares) was used from the four cross-sectional household surveys. This focus on the smallholder sub-sample was driven by critical differences and constraints for commercialisation which makes this group significantly different from medium-scale farmers.

\section{Household Survey}

The APRA household surveys purposively selected areas in each of the four countries where smallholder farmers were increasingly engaging with domestic and/or international markets and trade and selling their produce. The survey used a structured core questionnaire to collect data from the randomly selected households on plots cultivated, crops grown and sold, and incomes. The questionnaire also asked for extensive information on other topics, including household characteristics, asset ownership and values and household income sources. Smallholder farmers in each country grow different crops, such as cassava, groundnut, maize, oil palm, rice, tobacco, mostly for market sales, and to a lesser extent for home consumption, while other crops, including pulses and vegetables, are also grown to a more limited degree.

Data from each household were collected through face-to-face interviews with the household head, and where the head was not available, we interviewed another adult family member with relevant knowledge of the survey questions. Interviews were carried out by a team of enumerators who were trained and supervised by the senior researchers. Use of a core set of questions in all four countries gives us relevant data on commercialised smallholder households from four different contexts (Chirwa et al. 2018).

Our datasets give us an opportunity to study commercialisation for sample households that are increasingly engaging with markets. On account of a different focus in each context, we do not pool the data across all the countries. Figure 1 reports the primary crop types ${ }^{6}$ for each country to help contextualise findings. Note that the primary crops are oil palm and cassava in Ghana; rice and maize in Tanzania; maize and cassava in Nigeria; and maize and tobacco in Zimbabwe.

Data from Ghana were collected in November and December 2017 in Ahanta West and Mpohor district, in the oil palm belt of South-Western Ghana. Our samples are distributed between three oil palm commercialisation models, based on contract and non-contract farming, classified as: (a) Formal: offered by Norpalm Ghana $\mathrm{Ltd}^{7}$

\footnotetext{
6 And some secondary crops.

7 Norpalm Ghana Limited (NGL) is a privately owned company involved in the cultivation and processing of oil palm. The company is located at Pretsea, a community in the Ahanta west district of the Western region. Established in the year 2000 after acquiring the then state-owned National Oil Palm Limited (NOPL) through divestiture, NGL's plantations now cover a total area of 4000 hectares.
} 


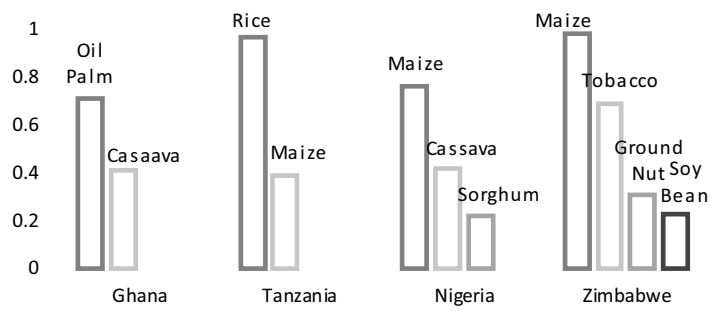

Note: Main crops grown by households ( $>20 \%$ households) in ascending order and the proportion of households reporting to growing each of those crops.

Fig. 1 Main crops grown by households-by country

and Benso Oil Palm Plantation ${ }^{8}$; (b) Incentive: offered by the medium-scale oil palm processor B-BOVID 9 (i.e., B-BOVID) and (c) Independent: independent smallholders with no formal contracts with buyers. 20 village communities were randomly selected at study site and a census was done for constructing a frame. A random sample of households was drawn across the villages and distributed proportionately across the three models.

The Tanzania data were collected in September and October 2017, for a sample of farm households across ten villages ${ }^{10}$ that were randomly selected from a list of all villages located within $30 \mathrm{~km}$ area from the Kilombero Plantation Limited (KPL) - a large-scale rice farm in Mngeta division. Given the importance of electrification in the area, stratified sampling was done by classifying villages in three categories according to their electricity status - had electricity by $2016 / 2017$ production season; gaining electricity between 2017/2018 and 2018/2019; and without electricity by 2019. A proportionate random sample of households was taken across the three groups; and, the sample consisted of small-scale farmers and those that were members of farmer groups applying the System Rice Intensification (SRI). ${ }^{11}$

The Nigeria survey was conducted in April and May 2018, using a two-stage sampling process. First, two states were purposively selected based on their rapid strides in development of commercial agriculture, Kaduna, in the northern part of the country, and Ogun State, in the southwest. Second, three Local Government Areas (LGAs) were selected systematically. Three senatorial districts were chosen in Kaduna and Ogun respectively, and one LGA was selected from each of the three senatorial districts based on land size and the concentration of farmers. In the final stage, a complete listing of all households controlling (owned, rented in, borrowed,

\footnotetext{
${ }^{8}$ Benso Oil Palm Plantation (BOPP) Limited, located in the Mpohor district of the Western region, was incorporated in 1976 jointly by Unilever PLC and the Government of Ghana (GOG) to produce Crude Palm Oil (CPO). BOPP was converted into a public limited liability company in 2004. The company is authorised to grow oil palm and other agricultural products; process oil palm fruits into palm oil; and trade in palm oil, palm kernels and other agricultural products.

${ }^{9}$ Building Businesses on Values, Integrity and Dignity (B-BOVID), was established in 2013 as an integrated agribusiness company based on the principles of social entrepreneurship. B-BOVID entered the oil palm purchasing space by buying Fresh Fruit Bunches at higher than the then prevailing market price as well as offering non-price incentives to farmers.

${ }^{10}$ Njage, Mkusi, Mchombe, Nakaguru, Ijia, Luvukila, Chita, Mngeta, Makutano and Itongoa.

${ }^{11}$ For a detailed description of SRI, see Nakano et al (2018).
} 
etc.) or operating five hectares and above (medium-scale) in all the selected LGAs was done. In each state, a proportional random sample of smallholders in the vicinity of the medium-scale farmers was drawn and that is examined in this paper.

The Zimbabwe survey was conducted in March and April 2018, and consisted of A1 resettlement farmers ${ }^{12}$ drawn from Mvurwi and the Concession areas of Mazowe District. These farmers were beneficiaries of the country's Fast Track Land Reform Programme and were allocated about 5 hectares of land to pursue agricultural livelihoods. Prior to 2007, these farmers were engaged in maize production for sale to traders in nearby Mvurwi and the Concession towns. After 2007, there has been rapid growth in tobacco production for sale through Harare-based auction floors. While Mvurwi has seen increased participation of smallholder farmers in non-food commercialisation with a rise in tobacco production, farmers in the Concession areas are cultivating maize for food and sale. Random samples of households were taken proportional to the size of the farming communities in the various schemes.

\section{Variables}

\section{Measuring Agricultural Commercialisation}

We measure commercialisation based on farmers' activities over the 12-month period prior to the survey. We consider all crops sold by the household during that entire period. Most smallholder households in our samples sold at least some of their harvest, allowing us to compute the level of commercialisation ${ }^{13}$ as the monetary value of sales made and the share of total crop output sold during the 12-months period covered by the survey, with a focus on the former. ${ }^{14}$

We also compute the household commercialisation index (HCI) that ranges from zero to hundred (Ogutu et al. 2020; Poulton 2017; Leavy and Poulton 2007; Rahut et al. 2010; Von Braun and Kennedy 1994). HCI is defined as:

$$
\mathrm{HCI}_{i j}=\frac{\sum_{j=1}^{n} \mathrm{gvs}_{i}}{\sum_{j=1}^{n} \mathrm{gvp}_{i}}
$$

$\mathrm{HCI}_{i j}=$ Household Commercialisation Index of $i^{\text {th }}$ household across all $j=1, \ldots, n$ crops in the past 12 months; gvs $_{i}=$ Gross Value of all crop sales for the $i$ th household in the past 12 months; $\operatorname{gvp}_{i}=$ Gross Value of all crop production for the $i$ th household in the past 12 months. HCI gives an indication of the extent to which household crop production is oriented toward the market, with a value of zero signifying total

\footnotetext{
12 The Fast Track Land Reform Programme (FTLRP) that unfolded from 2000 had two types of allocation: A1 smallholder farms, either as villagised arrangements or with self-contained plots; and A2 medium-scale farms, with sizes dependent on agro-ecological region (for more detail, see Scoones et al. 2010).

13 Rather than simply identifying commercialised and non-commercialised ones.

14 HCI will identify the proportion of sale from harvests without differentiating households that sell say $\$ 100$ from a household that sells $\$ 1,00,000$. To account for differences in such numbers, our key commercialisation indicator will be the value of sales made by the households.
} 
subsistence and a value closer to 100 implying very high levels of commercialisation. For the calculation of the commercialisation index, we imputed price data for each farmer using the quantity of sales and the value of sales reported in our data. We find that smallholder farmers often sell to different outlets and to a range of actors, hence averaging prices for each commodity would not be appropriate due to the large diversity in prices. To deal with this, we correct for any outliers in relation to the imputed prices using local averages, while preserving the variation in prices across different sale outlets for smallholders.

\section{Asset Ownership}

We identify asset ownership by aggregating across various household assets. These assets include (Filmer and Scott 2008): (i) production assets and consumer durables (hoe, spade, axe, sickle, shears, knife, sprayer and water pump, mattress, cooking stove, radio, television, mobile phone, fridge, bicycle, motorcycle and car/truck); (ii) land, and (iii) livestock. By including a range of assets, it is capturing overall household wealth, compared to what is captured by individual assets. ${ }^{15}$ For each household, we calculate per capita value for these categories of assets, using information on value of assets at the time of the survey. Asking about present value of assets allows an estimation of monetary amounts without the need for deflating. We use asset values in local currency units to determine our thresholds. Additionally, we construct two indexes using principal components analysis - an index for housing characteristics: type of material for walls, floor, and roof; and an index for access to basic resources: type of toilet, source of drinking water, type of fuel for cooking and lighting. These are individual indexes that are included as control variables in the analysis.

\section{Measuring Income Poverty}

We use 12-months of data on income from all farm and off-farm activities. The limitations of using income data over consumption expenditure data are well documented (Deaton and Zaidi 2002; World Bank 2014). However, given the extensive time required to collect expenditure data along with the fact that the commercialisation surveys were designed to collect a much broader range of data in addition, income data was the best option. Generally, reporting of incomes by rural households tends to be underestimated. The survey was designed to minimise this underestimation by included questions that allowed us to triangulate income estimates (i.e. we asked for income aggregates as well as specific income across a range of activities and employment). Farm income is calculated as the value of all agricultural output sold minus production costs (cost of inputs); off-farm income includes the income from all employed and self-employed activities of household members

\footnotetext{
15 Note that we do not attempt to disaggregate assets as the objective of the paper is to capture overall capacity, for which we make use of asset values, and the asset bundle arguably yields a more accurate picture than any single asset.
} 
and any transfers. The total net incomes are then equivalised using an adult equivalence scale factor. We use adult equivalised incomes in local currency units to map to asset thresholds. To compare thresholds, we report them both in local currency units and in international dollars, using the purchasing power parity (PPP) exchange rates. $^{16}$

The poverty line is a single (common) value, in the same units as equivalised income. We use the national absolute income poverty line in each country as the primary basis for identifying our threshold. (i) For Ghana, we use the poverty line of 982 cedis per adult per year as reported in the Ghana living standards survey round 7-GSS (2018) report. (ii) For Tanzania, we extrapolate based on the national poverty line at 36,482 Tshs, available in the World Bank (2015) report-to 36,4820 Tshs per year. (iii) The Nigeria national poverty line is extrapolated using information from the World Bank (2016) report to yield a poverty line of 130,000 Nairas a year. (iv) For Zimbabwe, using national poverty datum lines, we set the poverty line at 1000 Zimbabwean dollars. Additionally, we use calibrated relative poverty lines at two-thirds of the median household equivalised income to examine the robustness of our findings. We define income poverty as a dummy variable that takes a value of one if a household's per capita income falls below the poverty line, and zero otherwise (Foster et al. 1984).

\section{Empirical Strategy}

We examine if commercialisation is constrained by lower asset-based capacity of households and how that varies across different contexts. We begin by identifying an asset threshold to ascertain smallholder's current capacity for agricultural commercialisation. Our choice of threshold is based on mapping asset ownership to income poverty. Using the observed current income poverty thresholds from the samples of smallholders across the four countries, we estimate a unique asset poverty threshold per country. If the household is below this threshold, then it is classified as a lower capacity household-likely to face greater challenges to commercialise. If the household is above the threshold, then it is more likely to be resilient in face of the risks over time. Using the calculated minimum asset threshold, we identify each household's capacity for commercialisation. Next, we examine if commercialisation is constrained by low capacity in a given period, and the differences in commercialisation between lower and higher capacity households.

\footnotetext{
${ }^{16}$ In 2017, the PPP exchange rate was 1 US dollar=1.98 Ghanaian cedis, 102.46 Nairas, 708.42 Tshs, and 0.55 Zimbabwean dollars. Purchasing power parity conversion factor is the number of units of a country's currency required to buy the same amounts of goods and services in the domestic market as U.S. dollar would buy in the United States.
} 


\section{Identifying Capacity}

We draw on the asset poverty threshold calculation in Phadera et al. (2019), ${ }^{17}$ and adapt it for modelling cross-sectional variation in assets, to infer from it the current capacity to withstand risks from commercialisation. Our choice of this approach over those motivated earlier in Chaudhuri et al. (2002); Cahyadi and Waibel (2016); and, Chaudhuri (2003) is driven by the nature of our dataset, being the first round of a panel data collection, as well as the objective of this research to identify an asset based threshold.

We start by mapping the income poverty line, above which a household is considered non-poor, onto asset levels and we then create an asset-based threshold as below:

$$
\log \left(Y_{i}\right)=\alpha+\gamma \log \left(W_{i}\right)+\beta X+\epsilon_{i}
$$

where, $Y_{i}$ is per capita income of household $i$ in local currency units, $W_{i}$ is per capita value of total asset of household $i$ in local currency units and $X$ is a vector of controls correlated with household's income: age and sex of the household head, the number of years of education completed for the household head and household size. We estimate Eq. (1) using Ordinary Least Squares (OLS) and back out the coefficients. Using these estimated coefficients and median characteristics of the sample, we map the threshold adult equivalised income to household per capita asset level (Phadera et al. 2019) ${ }^{18}$ as:

$$
\log \bar{W}=\frac{\log \bar{P}-\hat{\alpha}-\widehat{\beta} X m}{\widehat{\gamma}}
$$

$\bar{P}$ is the income poverty line; the hat refers to estimated coefficients, $m$ subscripts represent the median value of the sample; and $\bar{W}$ is the estimated asset poverty threshold, below which we identify households as having lower capacities for commercialisation, and therefore, more vulnerable to risks from commercialisation.

\section{Capacity and Commercialisation}

Having identified capacity using asset thresholds, we explore its relationship with commercialisation, measured using the household's total value of crop sales. We control for the risk-reduction options and other factors that could influence household's commercialisation outcomes. Means and standard deviations for all these variables are reported in Table 4.

\footnotetext{
17 Appendix B2 in Phadera et al. (2019) maps the income/consumption poverty line, above which one is considered non-poor, to asset levels to create an asset based threshold. Note that we do not exploit the variance of the sample, as we are not estimating the household's vulnerability level i.e. the probability that a household with certain characteristics will be poor.

18 Phadera et al. (2019) subtract the value of an asset transfer and do the OLS estimation to estimate the coefficients.
} 
First, we examine differences for being lower capacity. Our primary dependent variable is Commercial- $(\log )$ total value of crop sales. ${ }^{19}$ We estimate the following specification where Capacity is a dummy variable that identifies households as lower and higher capacity (a value of 1 indicates lower capacity, and 0 otherwise):

$$
\text { Commercial }_{i}=\alpha+\gamma \text { Capacity }_{i}+\beta X+e_{i}
$$

$X$ is a vector of control variables that may influence household's commercialisation level that includes household characteristics (Ogutu and Qaim 2019; Dolislager et al. 2020; Arslan et al. 2020; Yaro et al. 2017): sex of the household head (Female headed $H H$ ), the age of the household head (Age HH head), the number of years of education completed for the household head (Schooling of HH head), household size (HH Size), total hired Labour (log hired labour days).

We also include a set of access indicators (Ogutu et al. 2020) to account for differential access to various services: house characteristics (Housing index), access to public services (Access to services index), access to road (Tarmac Road Access) and access to markets (Market Access), where market is defined as an established market place with many buyers and sellers of locally produced agricultural products.

Finally, other indicators important for a localised perspective on commercialisation, capturing both subjectively and objectively measurable dimensions (Chaves et al. 2018; Matthys et al. 2021): subjective perceptions of the household's poverty status as a proxy for poverty, typically positively correlated with commercialisation; dummy variables for commercial models in Ghana and for SRI training and membership in Tanzania, and village/area/LGA fixed effects to account for the sampling approach for each study. ei is the error term. The coefficient $\gamma$ captures the main relationship of interest: low capacity and commercialisation.

First, we estimate the model beginning with OLS regression methods using (log) total value of crop sales. Second, we use the propensity score to match higher capacity with lower capacity households in order to establish a meaningful comparison group using the nearest neighbour matching algorithm without replacement, matching each identified lower capacity household with its closest neighbour with similar characteristics. We apply propensity score matching (PSM) analysis (Caliendo and Kopeinig 2008) based on the conditional independence assumption (CIA) that once all of the observable covariates are controlled, the systematic differences in the commercialisation outcome between higher capacity and lower capacity smallholders are attributable to capacity based on asset ownership. ${ }^{20}$ The propensity score is

\footnotetext{
19 Additionally, for robustness analysis, we identified if a household is in one of the three groups identified using quartiles according to the household level of commercialisation (sales values) - highly commercialised (the upper quartile HC25), moderately commercialised (the middle two quartiles MC50), and the least commercialised (the lowest quartile LC25) households. Our choice of quartiles over other possible groupings follows the standard in the literature as in Ogutu and Qaim (2019) and others.

${ }^{20}$ We are able to control for observable sources of bias, but unobservable covariates may simultaneously influence capacity and commercialisation. We employ the standardised bias approach proposed by Rosenbaum and Rubin (1983) to assess the quality of matches by comparing before and after matching to check for remaining differences after conditioning on the propensity score.
} 
computed using a logit model with the same core covariates as those above, and we estimate the average treatment effect on the treated (ATT).

We acknowledge the limitations of our approach-first, the aim of the paper is not to draw a direct comparison across the four study contexts but rather to present the different localised narratives on their own-and where possible reflect on differences; second, the empirical strategy consists of an OLS to examine correlation between capacity and commercialisation, where we control for various characteristics that may be related with commercialisation, and also conduct various robustness checks, varying the threshold and measurement strategies; third, the propensity score matching with the cross-sectional data helps reduce biases in the distribution of covariates between groups differentiated by capacity, and we establish a meaningful comparison group- however, this cannot account for unobserved variables (selection) such as incentives, constraints and collective values that we attempt to account for using location specific fixed effects.

\section{Results}

We begin with descriptive analysis and then present three sets of results. First, we discuss our construction of capacity using a threshold. Second, using this threshold, we present a comparison of high and low capacity households on key characteristics. Third, we present the regressions of capacity on commercialisation, which constitute the central results of our analysis.

\section{Descriptive Analysis}

We begin by examining our sample of smallholder households across the four countries. Table 1 shows basic summary statistics for the full sample of smallholder households across the four countries. ${ }^{21}$

Using the commercialisation grouping above, we compare asset ownership values, adult equivalent incomes, poverty dummies using absolute and calibrated relative thresholds, our main commercialisation outcome- the value of crop sales, and HCI. All continuous variables are reported in $\log s$, as used to identify the threshold later. When we look at commercialisation groupings in the Appendix, as expected, there are significant differences in commercialisation levels and the proportion of sales (HCI) in all countries.

\footnotetext{
21 Appendix Table 6 reports the statistics by level of commercialisation, subdividing the sample into three groups using quartiles according to the household level of commercialisation (sales values) and compare the highly commercialised (the upper quartile HC25), moderately commercialised (the middle two quartiles MC50), and the least commercialised (the lowest quartile LC25) households. We use sales to sub-divide the groups as this helps compare households that sell a lot in monetary terms versus those that do not. HCI would group households based on proportion of sale from harvests without differentiating households that sell say $\$ 100$ from a household that sells $\$ 1,00,000$. We do not group based on these proportions from HCI to be able to categorise households using these monetary values. As a result the quartile groups are not equally distributed.
} 
Table 1 Summary statistics by country

\begin{tabular}{|c|c|c|c|c|}
\hline Variables & Ghana & Tanzania & Nigeria & Zimbabwe \\
\hline \multicolumn{5}{|l|}{ Assets } \\
\hline (log) per capita asset values & $\begin{array}{l}7.00 \\
(1.10)\end{array}$ & $\begin{array}{l}13.0 \\
(1.1)\end{array}$ & $\begin{array}{l}11.4 \\
(1.0)\end{array}$ & $\begin{array}{l}7.0 \\
(1.0)\end{array}$ \\
\hline \multicolumn{5}{|l|}{ Incomes } \\
\hline (log) adult equivalent income & $\begin{array}{l}7.2 \\
(1.4)\end{array}$ & $\begin{array}{l}12.7 \\
(1.2)\end{array}$ & $\begin{array}{l}12.0 \\
(0.9)\end{array}$ & $\begin{array}{l}7.0 \\
(0.9)\end{array}$ \\
\hline Absolute income poverty (dummy) & $\begin{array}{l}0.4 \\
(0.5)\end{array}$ & $\begin{array}{l}0.5 \\
(0.5)\end{array}$ & $\begin{array}{l}0.4 \\
(0.5)\end{array}$ & $\begin{array}{l}0.4 \\
(0.5)\end{array}$ \\
\hline Relative income poverty (dummy) & $\begin{array}{l}0.4 \\
(0.5)\end{array}$ & $\begin{array}{l}0.4 \\
(0.5)\end{array}$ & $\begin{array}{l}0.4 \\
(0.5)\end{array}$ & $\begin{array}{l}0.4 \\
(0.5)\end{array}$ \\
\hline \multicolumn{5}{|l|}{ Commercialisation } \\
\hline (log) total value of crop sales & $\begin{array}{l}6.8 \\
(2.4)\end{array}$ & $\begin{array}{l}11.3 \\
(5.0)\end{array}$ & $\begin{array}{l}12.9 \\
(1.0)\end{array}$ & $\begin{array}{l}7.9 \\
(1.6)\end{array}$ \\
\hline $\mathrm{HCI}$ & $\begin{array}{l}83.6 \\
(29.7)\end{array}$ & $\begin{array}{l}52.8 \\
(26.7)\end{array}$ & $\begin{array}{l}75.8 \\
(24.1)\end{array}$ & $\begin{array}{l}83.5 \\
(16.4)\end{array}$ \\
\hline Observations & 466 & 441 & 1068 & 419 \\
\hline
\end{tabular}

Means and standard deviations are shown in parentheses

On average, smallholder households in Ghana sell a very high percent of their farm output $-84 \%,{ }^{22}$ reflecting the fact that oil palm is a high value cash crop; the second key crop is cassava-also an important commercial crop in Southwestern Ghana. In Tanzania, sample smallholder households sell $53 \%$ of their farm output, on average, ${ }^{23}$ growing rice as a main crop; and the lower sales proportions reflect the use of rice for other purposes, such as home consumption, gifts, payments and other uses. Nigerian smallholder farmers in our sample sell a relatively high percentage of their production at approximately $76 \%^{24}$, growing maize as their primary crop, along with sorghum and cassava-all three with relatively high commercial value in domestic markets. Finally, in Zimbabwe, smallholders sell about $84 \%$ of their output, ${ }^{25}$ growing a combination of maize and tobacco, with both crops fetching high immediate commercial value, with the former sold mainly in domestic markets and the latter sold through auction houses regulated by the Tobacco Industry and Marketing Board for export.

As one would expect, more commercialised households in all countries, tend to have higher total asset values. We use these assets categories as a bundle and examine its correlation with commercialisation. Commercialisation and asset ownership

\footnotetext{
22 The LC, MC and HC households sell $62 \%, 88 \%$ and $96 \%$ respectively.

${ }^{23}$ While HC households sell 65\%, MC households sell $52 \%$ and the LC ones sell $28 \%$.

24 With LC, MC and HC selling 62\%, 77\%, and 86\% respectively.

${ }^{25} \mathrm{HC}$ households selling $90.5 \%$ on average, the MC group selling $85 \%$, and the LC ones selling about $73 \%$.
} 
are positively associated such that households having higher value assets tend to sell more in monetary terms but also sell more as a proportion of their harvests. The positive correlation suggests that assets may enable households to commercialise more easily.

We examine the relationship between asset ownership and commercialisation further by running a weighted local polynomial regression (without control variables) for each country, using the total value of all four asset categories. ${ }^{26}$ We note an increasing relationship between assets and commercialisation (Fig. 2)-i.e. higher asset endowments enables higher levels of commercialisation. The returns are rising at increasing rates at lower asset values and at decreasing rates at higher asset values-with the exception of Nigeria, where this relationship appears slow to change. Overall, these results are suggestive of the existence of some sort of threshold beyond which the returns no longer increase as rapidly.

This evidence points to the need for identifying such economic thresholds for commercialisation and examining the types of factors that can explain why certain households become trapped at lower ends of commercialisation and what types of interventions can pull these households beyond thresholds and towards commercialisation with better livelihood outcomes. The comparisons between more and less commercialised households are in line with our hypothesis of assets and incomes determining the capacity for commercialisation, however, these differences do not control for possible confounding factors. We control for confounding factors in the following sub-sections through multiple regression models and matching methods.

\section{Asset Thresholds}

Based on Eqs. (1) and (2), we map the income poverty line to asset threshold. Figure 3 in the appendix outlines the graphical illustration using the scatterplot and locally weighted regression regressions for the log of per capita incomes (y-axis) and the log of per capita asset values (x-axis). Using the estimated coefficients from the ordinary least squares regression (1) and the median characteristics of the sample, we map the threshold per capita income to the household per capita asset level as listed below in Table 2 .

For Ghana, the asset poverty threshold in natural $\log$ is $6.5(=\log (\mathrm{W}) \Longrightarrow$ $\mathrm{W}=\exp 6.5 \approx 665$ Ghanaian cedis or about 336 USD PPP). The Ghanaian threshold is the lowest, and suggests that smallholder farmer's higher capacity is identified by relatively low levels of assets per capita on average- such that these households may be commercialising with support from external schemes, in our case, oil palm commercialisation models based on contract farming that provides access to a variety of inputs required for production for sale.

\footnotetext{
26 The regression is weighted so that the central point gets the highest weight and points that are farther away receive less weight. The estimated regression line is then used to predict the smoothed values. The procedure is repeated to obtain the remaining smoothed values, which means that a separate weighted regression is performed for every point in the data.
} 

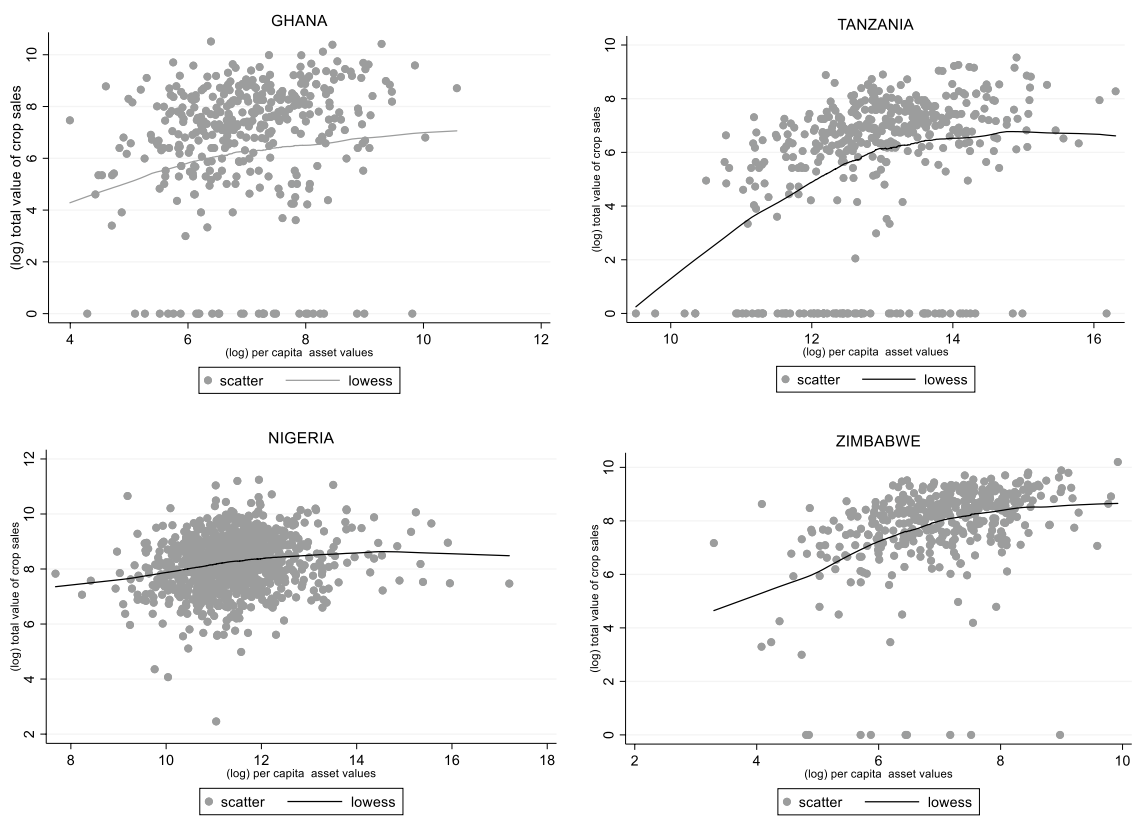

Notes: Dots represent $(\log )$ total value of crop sales made by the household. The line is the locally weighted regression line for each regression for $(\log )$ total value of crop sales on the $\mathrm{Y}$-axis and $(\log )$ per capita asset values on the $\mathrm{X}$-axis respectively.

Fig. 2 Locally weighted regression-Assets and commercialisation-by country. Notes Dots represent $(\log )$ total value of crop sales made by the household. The line is the locally weighted regression line for each regression for (log) total value of crop sales on the Y-axis and (log) per capita asset values on the $\mathrm{X}$-axis, respectively

In Tanzania, the asset poverty threshold in natural $\log$ is $13(=\log (\mathrm{W}) \Longrightarrow$ $\mathrm{W}=\exp 13 \approx 442,413$ Tshs or about 624 USD PPP. Tanzanian household's higher capacity is identified by moderately average resources, suggesting that the main crop being rice, smallholders are likely benefitting from intensification in our study areas.

For Nigeria, the asset poverty threshold in natural $\log$ is $10(=\log (\mathrm{W}) \Longrightarrow$ $\mathrm{W}=\exp 10.6 \approx 40,134$ Nairas or about 392 USD PPP. Nigeria yields one of the lower thresholds-a potential signal that smallholder households in this sample possibly reap some benefits from their linkages with medium-scale farmers and hence are able to commercialise even with relatively lower asset ownership.

Finally, for Zimbabwe, the asset poverty threshold in natural $\log$ is $6.7(=\log (\mathrm{W})$ $\Longrightarrow \mathrm{W}=\exp 6.3 \approx 812$ Zimbabwean dollars or about 1479 USD PPP. The threshold for Zimbabwe is highest relative to the other countries, likely explained by the sample selection that focused on households growing tobacco as the key crop (along with maize), a high value commercial crop usually sold at auctions, but also attracts a huge amount of risk. 
Table 2 Asset threshold by country

\begin{tabular}{|c|c|c|c|c|}
\hline Units & Ghana & Tanzania & Nigeria & Zimbabwe \\
\hline Local currency units & $\begin{array}{l}665 \text { Ghanaian } \\
\text { cedis }\end{array}$ & 442,413 Tshs & 40,134 Nairas & 812 Zimbabwean \$ \\
\hline USD PPP & 336 & 624 & 392 & 1479 \\
\hline
\end{tabular}

\section{High Capacity and Low Capacity Households}

Many households were observed to have higher capacity for commercialisation. Table 3 presents summary statistics for the full sample of smallholder households across the four countries, subdividing the sample into two groups according to thresholds identified above. We compare the Higher Capacity (above the thresholds) with the Lower Capacity (below the thresholds) households in terms of the main variables of interest along with control variables.

Higher capacity households sell significantly higher total value of produce in all countries. This finding suggests that capacity is reflected in agricultural sales. When we use a relative measure of commercialisation - the value of sales as a proportion of the value of produce ( $\mathrm{HCI}$ - -we find that $\mathrm{HCI}$ is higher for higher capacity households in Ghana, Tanzania and Zimbabwe; with the exception of Nigeria, where HCI is lower for higher capacity households, on average. We use our absolute measure of commercialisation $(\log )$ total value of crop sales for all analysis to follow, owing to reasons cited in section "Measuring Agricultural Commercialisation".

Using the capacity grouping, we further compare characteristics that are likely to explain differences in household potential for commercialisation. There are certain characteristics that differentiate higher capacity households across all countries, but there are also different factors shaping capacity across countries, likely owing to the differential nature of opportunities for commercialisation in the four countries. We draw attention to some of these differentiating factors below.

Average years of schooling of the household head is significantly higher for the higher capacity households in all countries. This indicates that returns to schooling for commercialisation is high across the four study contexts, also aligning with findings in the literature that point to more commercialised households having higher levels of education (Ogutu and Qaim 2019). Higher capacity households are primarily headed by younger household heads, on average, in Ghana, Tanzania and Nigeria, but not in Zimbabwe; these differences are, however, statistically significant only in Tanzania and Nigeria. This result suggests youth and youth-led households being overrepresented in farming (Dolislager et al. 2020; Carreras et al. 2020; Mutabazi et al. 2013). It may also reflect the involvement of youth in specific crops and crop related activities; and, potential income- and poverty 'penalties' (Arslan et al. 2020) faced by younger lower capacity households.

Higher capacity households are also dominantly male-headed in all countries though the difference is statistically insignificant for three of our study areas. 


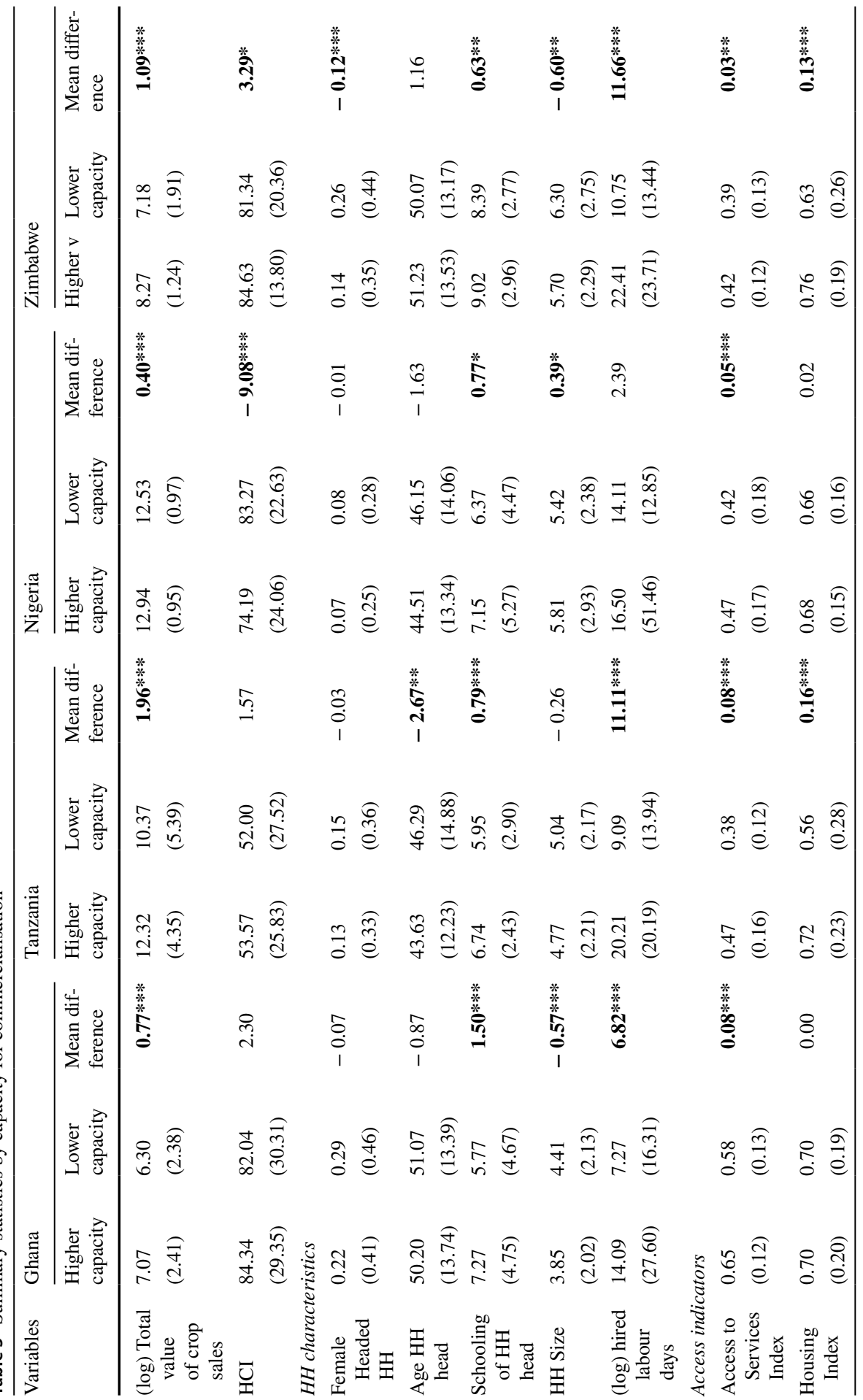




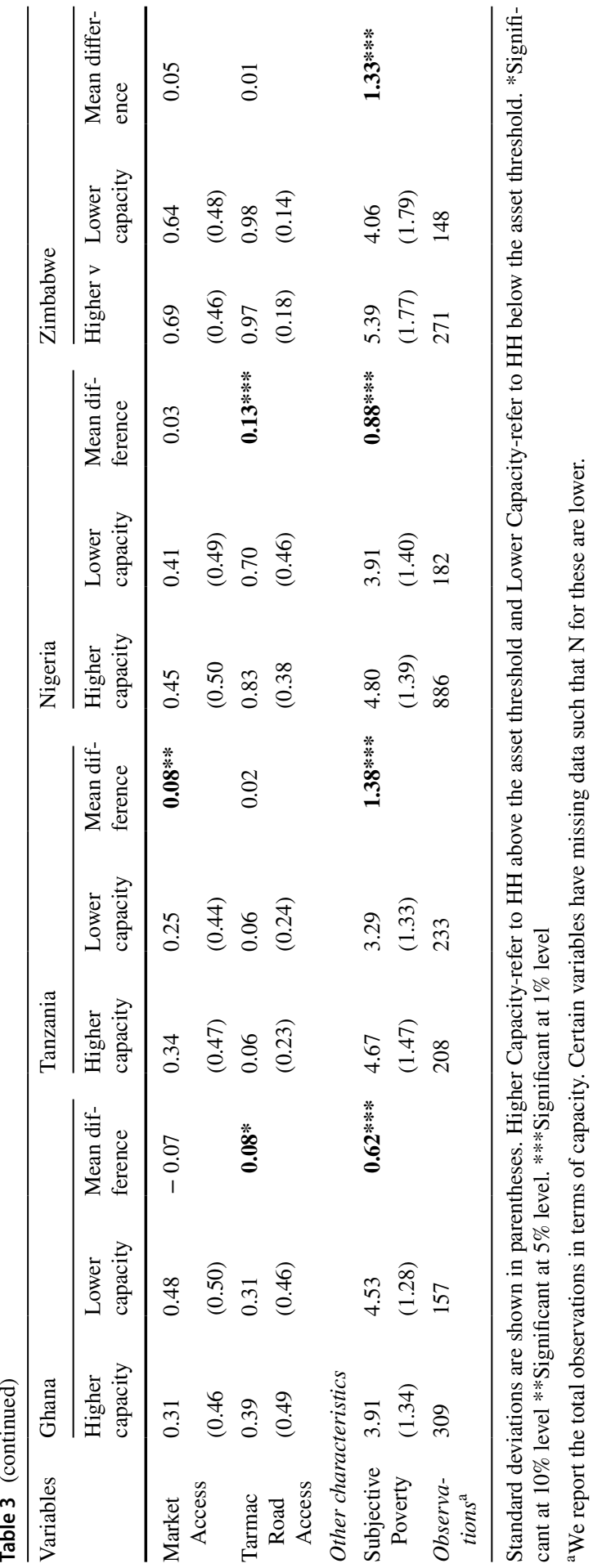


However, in Zimbabwe, where gender of household is significant, we find a relatively larger proportion of female headed households $(26 \%)$ than male headed ones $(14 \%)$ identified as low capacity, potentially reflecting the nature of production of one of the primary crops-tobacco.

There is noticeable variation in household size for the capacity groups across the countries. Households identified as higher capacity in Ghana, Tanzania and Zimbabwe have smaller households-and this difference is significant in Ghana and Zimbabwe. Interestingly, in Nigeria, we find higher capacity is significantly related to larger households, on average. This finding may be linked with hired labour, as also described in the literature (Yaro et al. 2017; Hall et al. 2017) as there are significant differences between higher capacity and lower capacity households, with the former using greater hired labour in all countries except Nigeria.

Looking at the access indicators, we find stark differences in access to services across all contexts-with higher capacity households having significantly better access to public services, such as type of toilet, source of drinking water, type of fuel for cooking and lighting. In terms of housing the picture varies by countrywith significantly better housing associated with higher capacity households in study locations in Tanzania and Zimbabwe, but this difference is insignificant in Ghana and Nigeria.

No clear picture emerges when we examine market access. Only in Tanzania do higher capacity households report significantly greater access to markets. In the other contexts, access to an established market place appears less importantperhaps as smallholders are selling through other routes, for instance through contract farming in Ghana, and auctions for tobacco in Zimbabwe. In terms of access to a tarmac road, higher capacity households in Ghana and Nigeria report significantly greater access, while we find no significant difference for the higher and lower capacity households in the other two countries.

Finally, we find stark and significant differences in terms of subjective perceptions of poverty between the two capacity groupings across the four countries (Chaves et al. 2018). What is interesting is that higher capacity households rank themselves much higher (less poor) on the subjective scale, on average, in Tanzania, Nigeria and Zimbabwe; clearly, in this case there appears to be a likely correlation between household perceptions about their welfare and their asset ownership. The exception to this-in Ghana-is counter-intuitive, but may be explained by higher capacity households having higher levels of participation in sales contracts and other collective farming forms in other words, they have security of sales/income for the short to medium term (Dzanku et al. 2020).

Overall, and at an aggregate level for the household, capacity for commercialisation is marked by a youth and gender dimension in relation to the household head. Additionally, there appear to be trade-offs in terms of family and hired labour, as well as important links for household welfare and subjective perspectives on poverty. 


\section{Commercialisation and Lower Capacity}

Based on Eq. (3), Table 4 presents the results from the OLS estimations-presenting the coefficients, their standard errors, and the significance of the results. Panel $A$ presents results for Ghana in columns (1)-(3); results for Tanzania are in columns (4)-(6) in Panel B; Nigeria results are in columns (7)-(9) in Panel C; and, finally, results for Zimbabwe are presented in columns (10)-(12) in Panel D. Each panel provides the OLS coefficients using commercialisation levels measured as (log) total value of crop sales. ${ }^{27}$ We do not pool the country datasets for this analysis, given the varied contexts and sampling strategies. Instead, we examine lower capacity and commercialisation in different contexts.

We note that while there may be concerns of correlation between our key variable of interest and the disturbance term - especially for capacity, we try to address this by controlling for various characteristics that may be related with commercialisation; and, to control for common area specific features, we add location specific fixed effects. ${ }^{28}$ Additionally, we also check for multicollinearity between capacity and the other control variables - and the tests suggest that multicollinearity is not a problem in our regression model. ${ }^{29}$

We begin with the OLS results. The most robust result across all countries and specifications is the negative relationship between being a lower capacity household and commercialisation. This relationship is also statistically significant across all estimations - with one exception: while commercialisation levels are approximately $30 \%$ lower for lower capacity households in Ghana, as inferred from column (1), the result is statistically insignificant. This result for Ghana may reflect the fact that the majority households in our sample enter formal contracts with buyers, implying such that capacity in terms of resources could be less of a constraint as they are better protected from likely risks from commercialisation. In other words, the institutional arrangements for sale and market access will not always be determined at a household level. Further, when we examine the OLS results by the capacity groupings for Ghanaian households in columns (2) and (3), while we find an overall positive relationship between commercialisation and hired labour, the relationship holds in terms of significance for the lower capacity households only—suggesting the likely significant returns from hiring labour for lower capacity households. Further, lower capacity households with access to a tarmac road have significantly lower levels of commercialisation, as opposed to the higher capacity ones where the coefficient is positive but insignificant.

Next, commercialisation levels for lower capacity households in Tanzania are $65 \%$ lower than higher capacity households-and this difference is statistically

\footnotetext{
${ }^{27}$ The dependent variable is in logs and lower capacity is a dummy variable-hence the coefficient $\gamma$ can be used to compute the percentage difference using the exponential as follows: $100 \times\left(e^{\gamma}-1\right)$.

${ }^{28}$ We present the results without location fixed effects in the appendix. Overall, the results are robustand results change only in terms of coefficient size. This suggests that in modelling the relationship between capacity and commercialisation, it is important to control for common area specific features.

${ }^{29}$ We detect for multicollinearity using the variance inflation factor (VIF), which measures the correlation and strength of correlation between capacity and the control variables in our regression model. The tests are attached in Supplementary Appendix Table A1.
} 


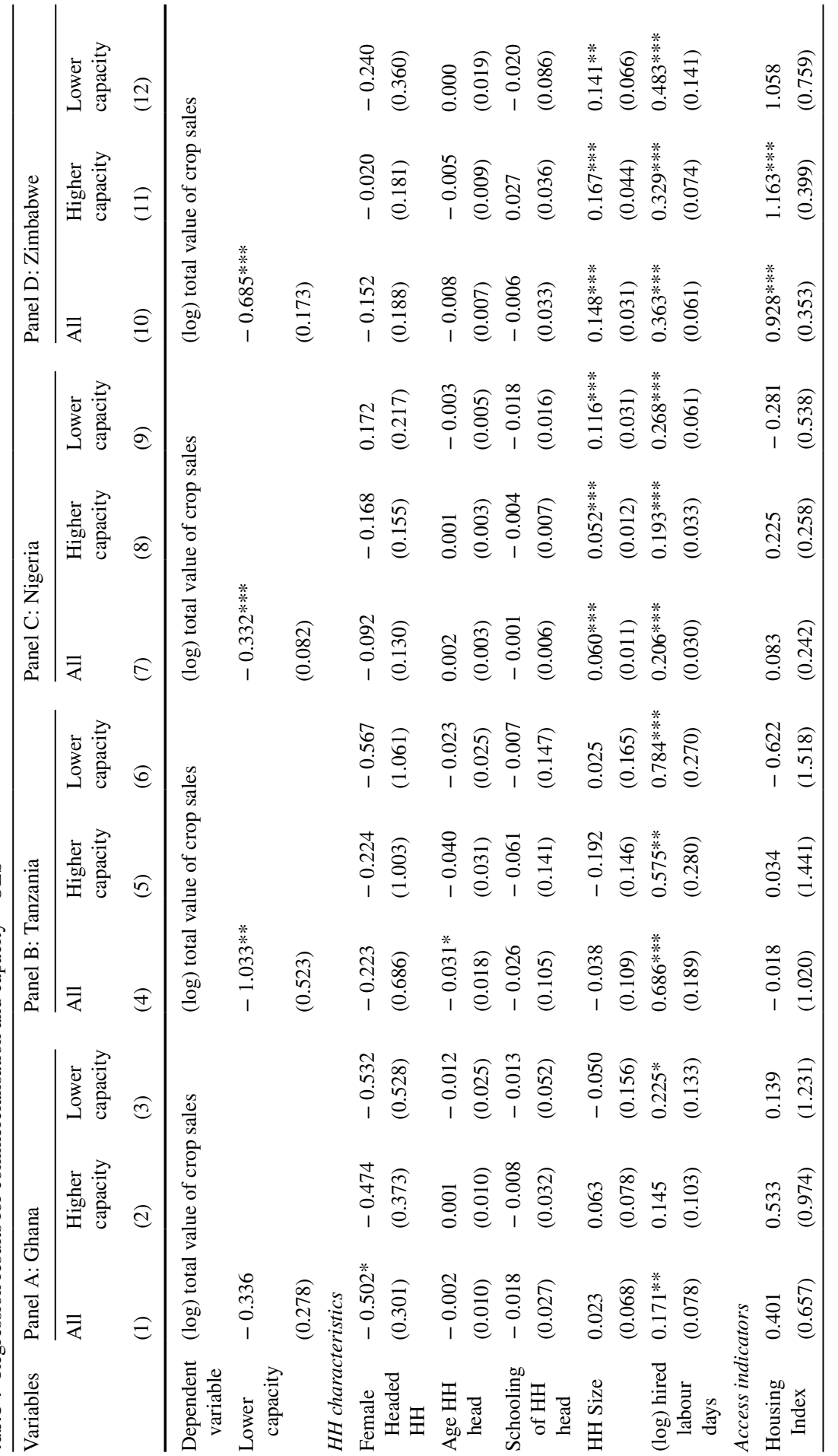




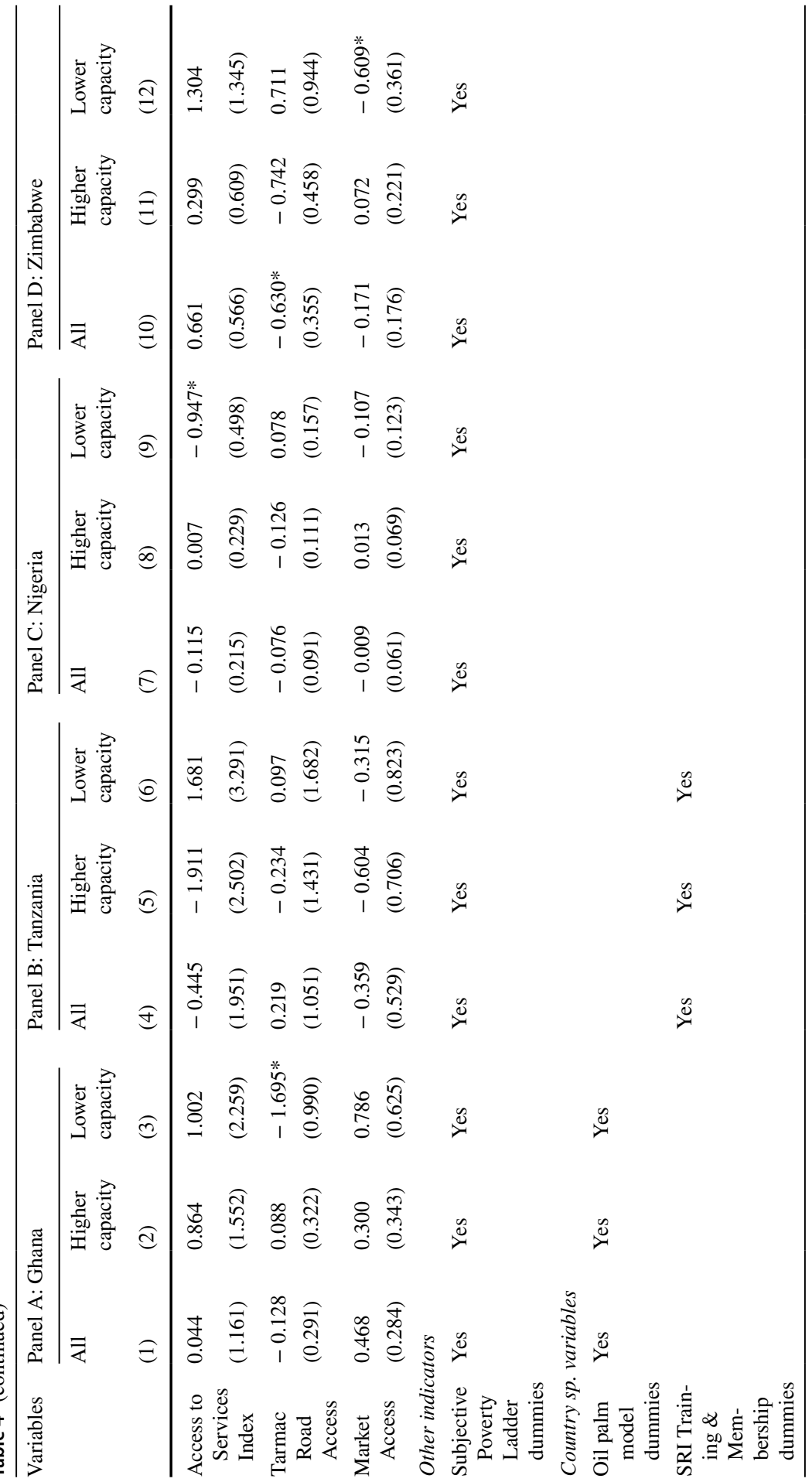




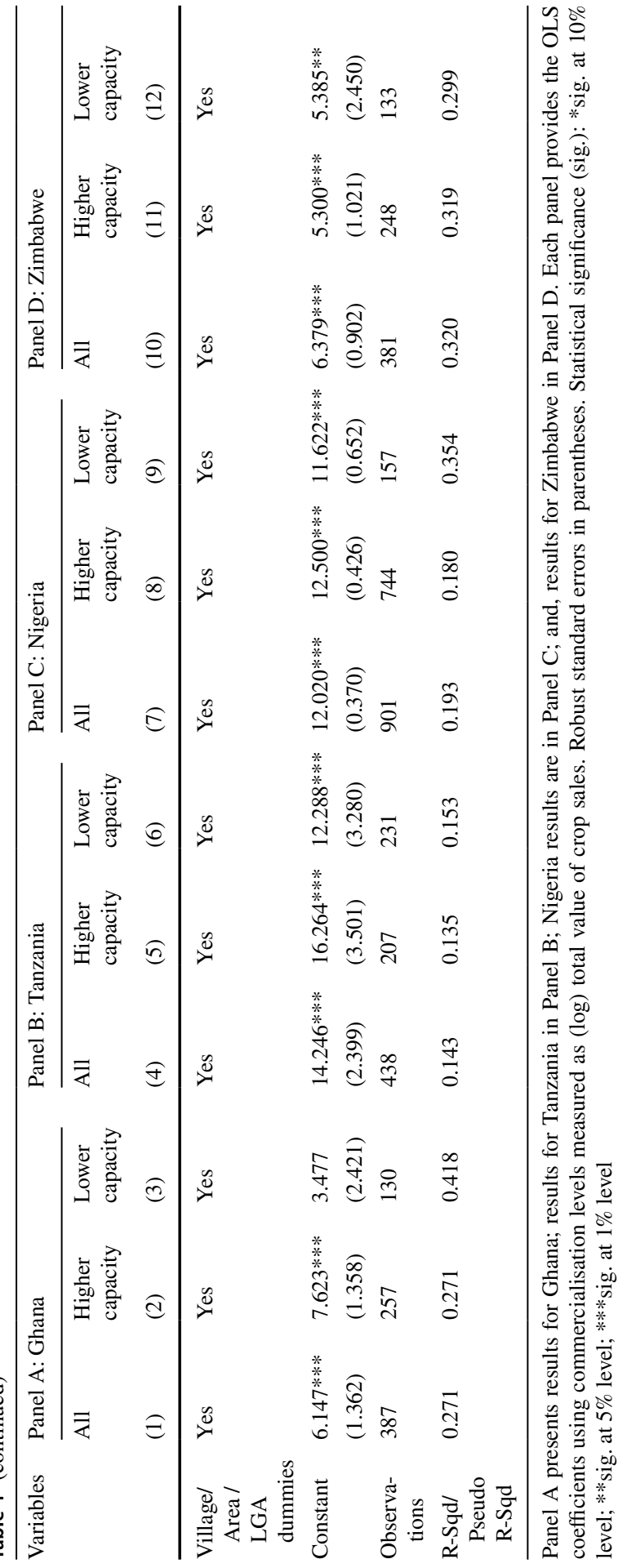

站。 
significant, as reported in column (4), affirming low capacity being a constraint to achieving higher commercialisation levels. Among the control variables, we find that for the overall sample, younger households on average are commercialising at relatively higher levels, but this difference is no longer statistically significant when we examine the OLS results by capacity groupings in columns (5) and (6). Further, and similar to the case for Ghana, we find that hired labour is positively and significantly linked with higher commercialisation, and this result remains statistically significant for the results with the capacity groupings.

When we look at Nigeria, we find that commercialisation levels are approximately $28 \%$ lower for lower capacity households, as inferred from column (7), and the result is statistically significant. Nigerian smallholder households are therefore constrained by lower capacity in terms of assets. Notably, we find positive and significant coefficients for household size and hired labour across columns (7)-(9), such that the results hold across the overall sample and the sub- samples by capacity groupings. Further, for lower capacity households, those with better access to public services appear to have lower levels of commercialisation.

Finally, results for the Zimbabwe sample suggests that lower capacity households have $50 \%$ lower commercialisation levels, and this is statistically significant (column 10). Again, similar to Nigeria, we find positive and significant coefficients for household size and hired labour, both, for the overall sample as well as for the results with the capacity groupings. Additionally, we find a positive link between housing characteristics and commercialisation for the overall sample and te higher capacity households. Further, lower capacity households with market access have significantly lower levels of commercialisation.

Overall, the aforementioned results suggest that when controlling for various household characteristics, access and other factors, commercialisation is likely constrained by lower capacity, highlighting the need for targeted support for those at the margins and with limited assets. Across the four study contexts, we witness some of the most pronounced and significant constraints associated with lower capacity households in Tanzania.

To examine the robustness of our baseline results, we undertake two estimations. First, we use the value of assets to replace capacity and review the results (Appendix Table 8); Second, we use an alternate threshold using relative poverty (Appendix Table 9). We note that our results on capacity and commercialisation are robust to using asset values - per capita assets are positively related with commercialisation across all specifications, such that higher assets reflects higher capacity to commercialise. This result is also statistically significant across most estimations. The results are also robust to using the alternate threshold of relative poverty — we note that the capacity and commercialisation relationship remains negative across all countries. This result is also statistically significant for Tanzania, Nigeria and Zimbabwe, again with the exception of Ghana where we lose in terms of significance. The key results for hired labour and household size also hold with the alternate threshold.

Although the above results indicate that lower capacity households are commercialising at lower levels, we now attempt to examine this for more closely comparable groups. Capacity as measured by the asset threshold is not random and is likely determined by a set of covariates-so, we implement the propensity score matching analysis using nearest neighbour method (details and covariate balancing tests in Appendix 
Tables 10 and 11). In Table 5, we show the results for the relationship between lower capacity and commercialisation by comparing farmers that are observationally very similar to overcome selection on observables. We find further evidence that lower capacity does, in fact, constrain commercialisation outcomes across all four contexts. We find differences between higher capacity and lower capacity household, albeit the identification of capacity itself reflects the different risk reducing factors.

While we saw earlier that commercialisation levels did not differ significantly for Ghana's oil palm producers, once we controlled for different factors, with the matched sample, we find evidence that lower capacity is in fact a significant constraint, with lower capacity households at $41 \%$ lower levels of commercialisation (than $30 \%$ inferred earlier), even if smallholders may rely on contract farming for some support-as also found by Cahyadi and Waibel (2016) for Indonesia. In Tanzania, with the matched sample, we find that lower capacity households have $81 \%$ lower commercialisation levels (than about $65 \%$ inferred earlier) — suggesting the likely significant risk faced by these households. Looking at Nigeria and Zimbabwe, we find lower capacity households have approximately $32 \%$ and $55 \%$ lower commercialisation levels (than $28 \%$ and $50 \%$ respectively). Hence, using the matched sample across all countries, we find relatively higher differences in commercialisation between the lower and higher capacity households; and, this difference is greatest for the rice growing sample in Tanzania.

Imposing the common support condition yields the matched groups. Based on the balancing tests (see Appendix Table 11) after matching, the differences in all covariates between the two groups are no longer significant at 1\%, the pseudo R-Square decreased in all cases and the likelihood ratio test is insignificant. This indicates that there are no systematic differences in the distribution of covariates between the lower and higher capacity groups for the matched samples. We also see that a selection bias exists, as shown by the significant coefficients for unmatched households, such that certain characteristics make it more likely for households to be lower capacity. ${ }^{30}$

Our empirical results provide directions for supporting smallholder commercialisation.

- We find that our Ghanaian sample in the oil palm belt of South-Western Ghana is commercialising with relatively lower levels of resources on average, likely owing to support from buyer contracts; yet, lower capacity poses a constraint with significantly greater differences in commercialisation levels between lower and higher capacity households.

- In Tanzania, the asset poverty threshold is moderate, suggesting that smallholders in the rice belt Mngeta division are benefitting to a certain extent from applying SRI, but surprisingly, still need the most significant resources to support them in the face of risks; and, we find the greatest differences in commercialisation levels between lower capacity and higher capacity households

- For Nigeria, the asset poverty threshold is low-a potential signal that these smallholder households in selected senatorial districts in Ogun and Kaduna

$\overline{30}$ We report results with an alternate matching procedure in the supplementary appendix to the paper. 
clearly benefit from linkages with medium-scale farmers; and, we find a corresponding smaller difference between lower and higher capacity households.

- Finally, for Zimbabwe, the asset poverty threshold is high and lower capacity is a constraint, likely explained by the sample selection that focused on households growing tobacco as the key crop (along with maize) in Mvurwi and the Concession, a high value commercial crop usually sold at auctions, attracting a huge amount of risk.

\section{Conclusions and policy implications}

In this paper, we looked at assets as a determinant of smallholder commercialisation across four different country contexts and different crop portfolios. Overall, the evidence shows that assets may enable or constrain smallholders from becoming more commercialised.

We defined capacity using asset thresholds that can be understood as the ability to minimize exposure to risks. It is no doubt that this differs across local contextssuch as being part of contract farming or benefitting from linkages with mediumscale farmers or simply growing certain types of crops. We show that a smallholder household's capacity, which is essentially a proxy for poverty, determines its ability to commercialise. Poverty, therefore, acts as a constraint to taking advantage of commercialisation and deal with risks, such that the obvious policy implications are that households with lower assets are likely to need a boost to help them commercialise.

Smallholders facing greater risks and especially women and youth-headed households will therefore benefit from interventions that can provide resource support for commercialisation. This could be in the form of credit, targeted assets and training-depending on the crop and sector in which commercialisation is happening. We see also that household demographic factors play an important role in the degree they are able to commercialise. Gender and age of the household head, education and household size influence not only capacity but also commercialisation potential. Therefore, targeted interventions to support farmers wishing to increase marketed output can be tailored to household types.

Further, interventions could be targeted by capacity in any given period. For instance, our findings about the relationship between lower capacity and commercialisation levels suggest that highly commercialised households are significantly less likely to be lower capacity. Additionally, the results for household size and hired labour reveal some likely trade-offs between family labour and hired farm labour, as lower capacity households are likely to use much less hired labour.

However, capacity only reveals the households' potential to commercialise. The household may or may not realise this potential. For development policies, it is important to be able to specifically target households rather than following a one size fits all approach. A measure of commercialisation potential therefore helps identify especially those that are more likely to drop out of commercialisation in the future.

One may argue that the next relevant question relates to the ability of smallholders to actually realise this potential. What could explain why some smallholders achieve their potential, while others are less successful? Ideally, we will use panel 
Table 5 Capacity and commercialisation before and after propensity score matching

\begin{tabular}{|c|c|c|c|c|c|}
\hline \multirow{2}{*}{$\begin{array}{l}\text { Dependent variable: } \\
\text { (log) Total value of } \\
\text { crop sales }\end{array}$} & \multicolumn{2}{|l|}{ Before matching } & \multicolumn{3}{|l|}{ After matching } \\
\hline & Lower capacity & Higher capacity & Lower capacity & Higher capacity & ATT \\
\hline Ghana & 6.30 & 7.07 & 6.30 & 6.83 & $\begin{array}{l}-0.53 * * * \\
(0.300)\end{array}$ \\
\hline$N$ & 130 & 309 & 130 & 130 & \\
\hline Tanzania & 10.37 & 12.32 & 10.64 & 12.32 & $\begin{array}{l}-1.68 * * * \\
(0.471)\end{array}$ \\
\hline$N$ & 233 & 208 & 208 & 208 & \\
\hline Nigeria & 12.53 & 12.94 & 12.61 & 12.99 & $\begin{array}{l}-0.39^{* * *} \\
(0.111)\end{array}$ \\
\hline$N$ & 182 & 886 & 157 & 157 & \\
\hline Zimbabwe & 7.18 & 8.27 & 7.22 & 8.03 & $\begin{array}{l}-0.81^{* * *} \\
(0.210)\end{array}$ \\
\hline$N$ & 148 & 271 & 133 & 133 & \\
\hline
\end{tabular}

The propensity score is computed using a logit model, and we estimate the average treatment on the treated (ATT) using the nearest neighbour matching algorithm. Robust standard errors in parentheses. Statistical significance (sig.): *sig. at $10 \%$ level; **sig. at $5 \%$ level; ***sig. at $1 \%$ level

data to predict the routes of commercialisation given capacity. Future rounds of data collection in the same countries and sites will enable us to observe these dynamic routes where we will be able to observe specific pathways for households, and also predict the likelihood to stay on them. This will help in the design of interventions targeted at specific capacity-building measures that can help smallholders realise their potential when facing barriers to, and risks from, commercialisation.

\section{Appendix}

See Tables 6, 7, 8, 9, 10, 11 and Fig. 3. 


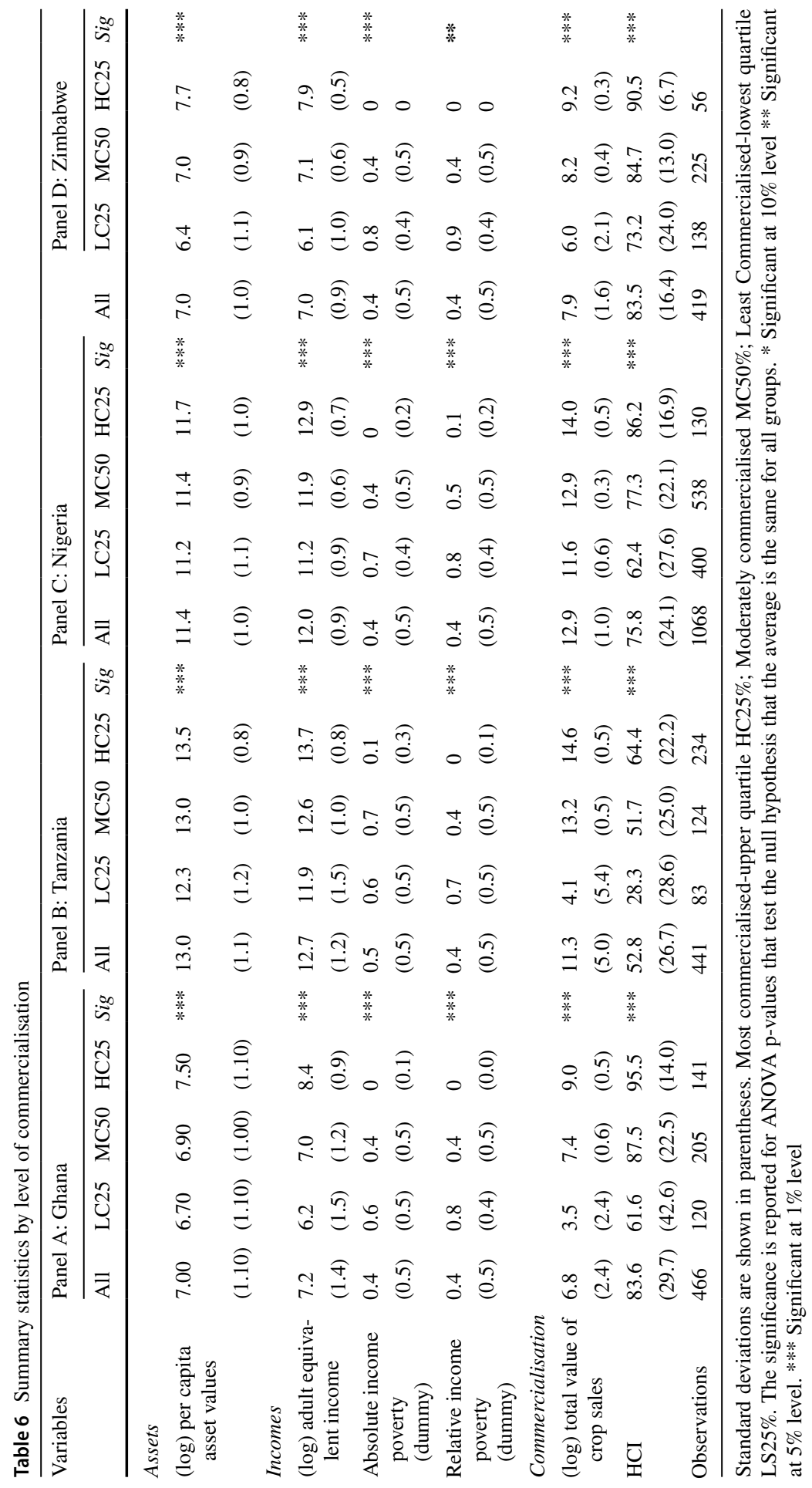




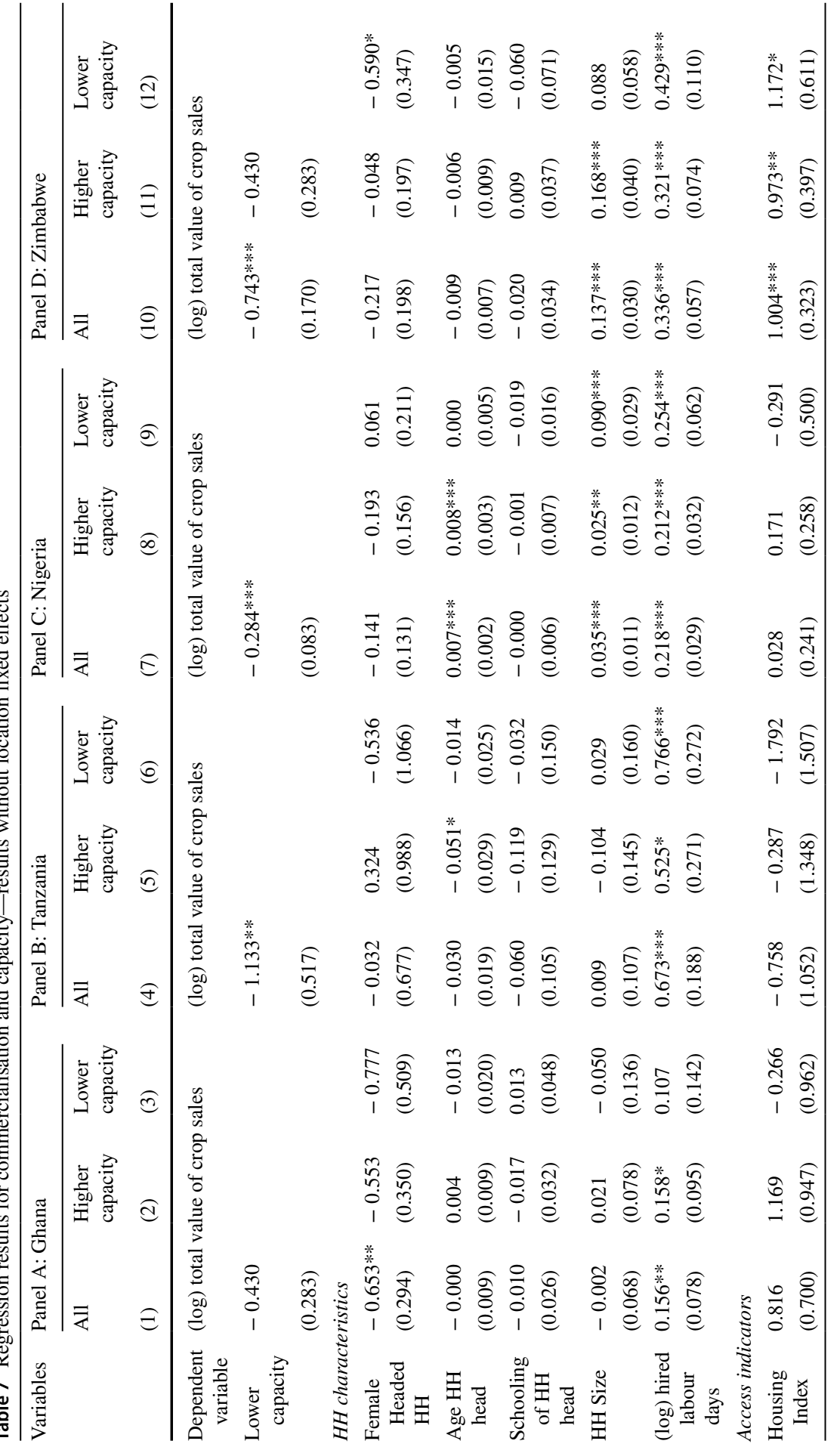




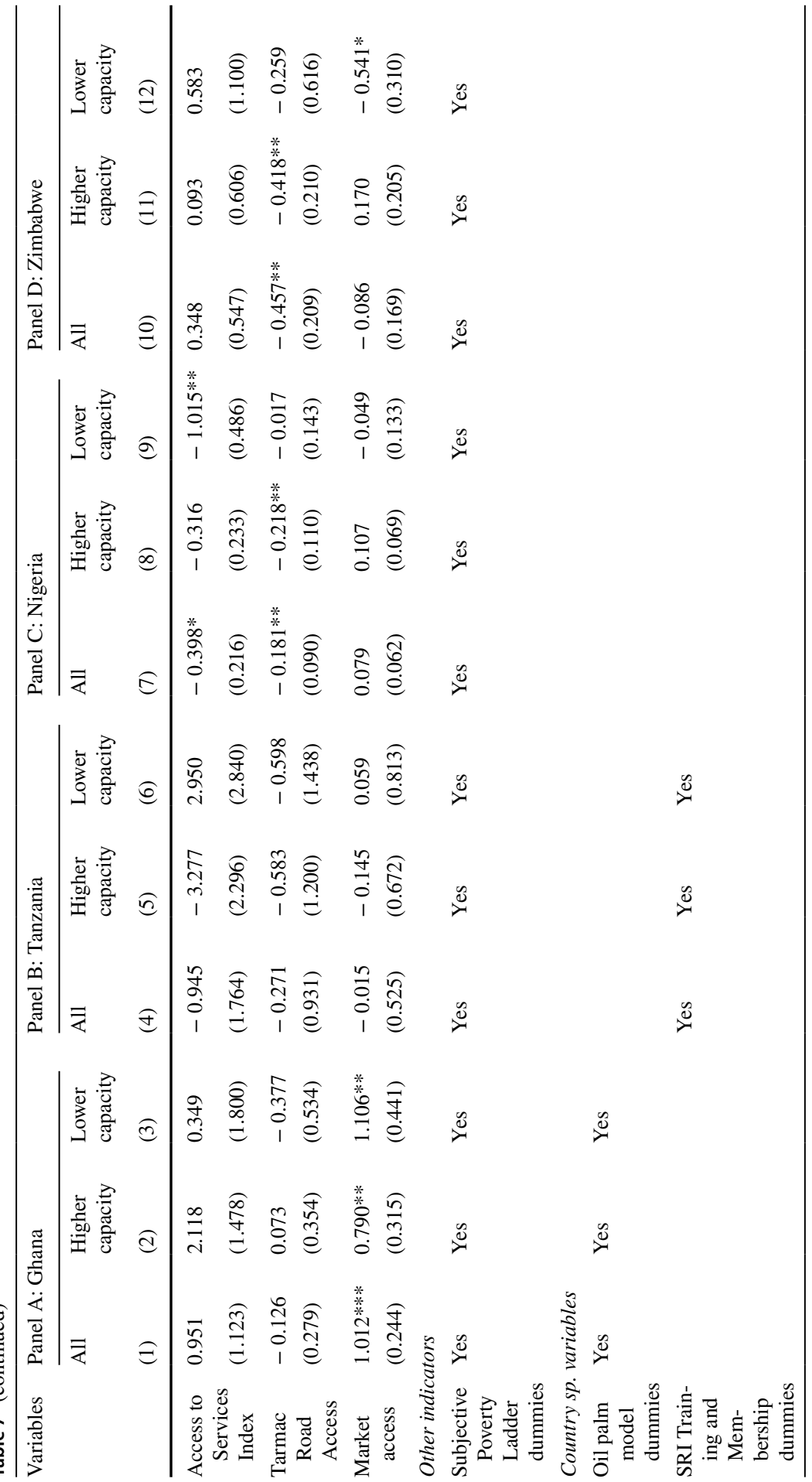




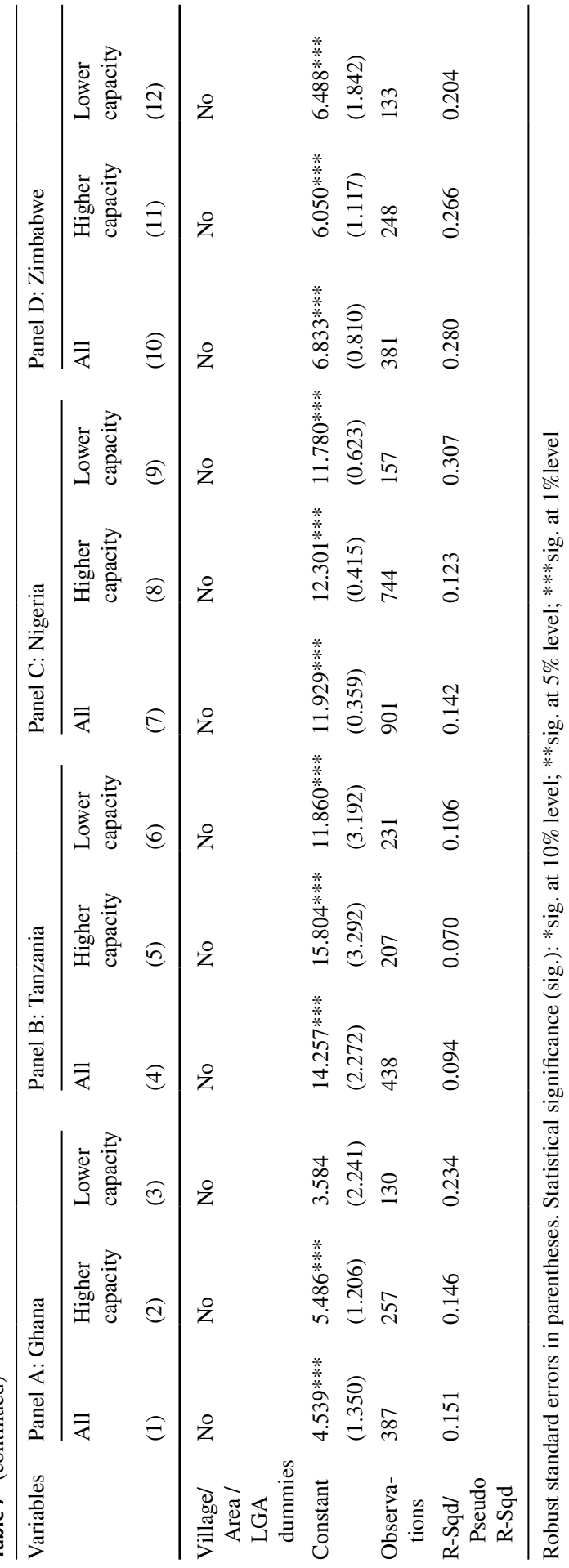

站。 


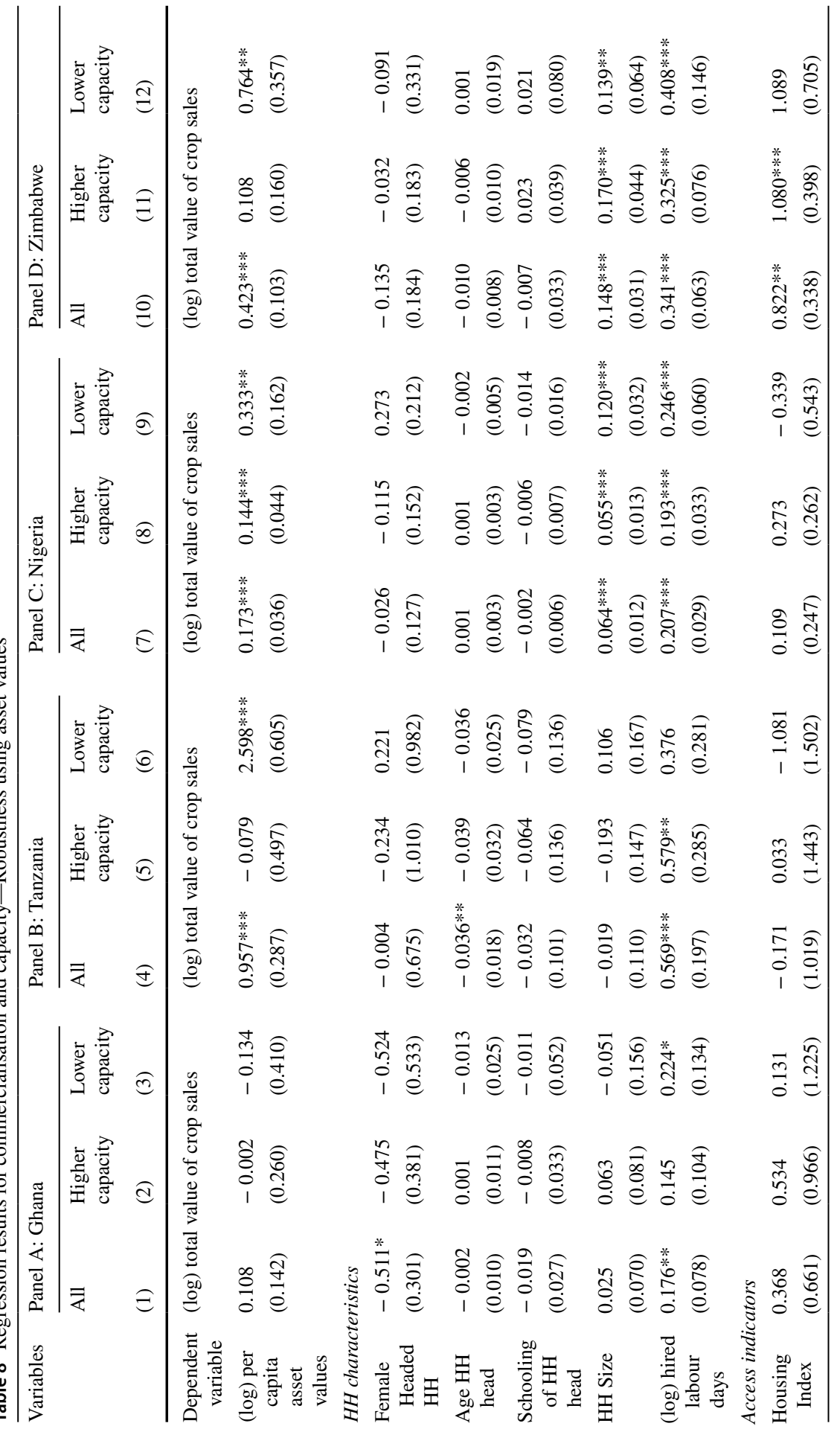




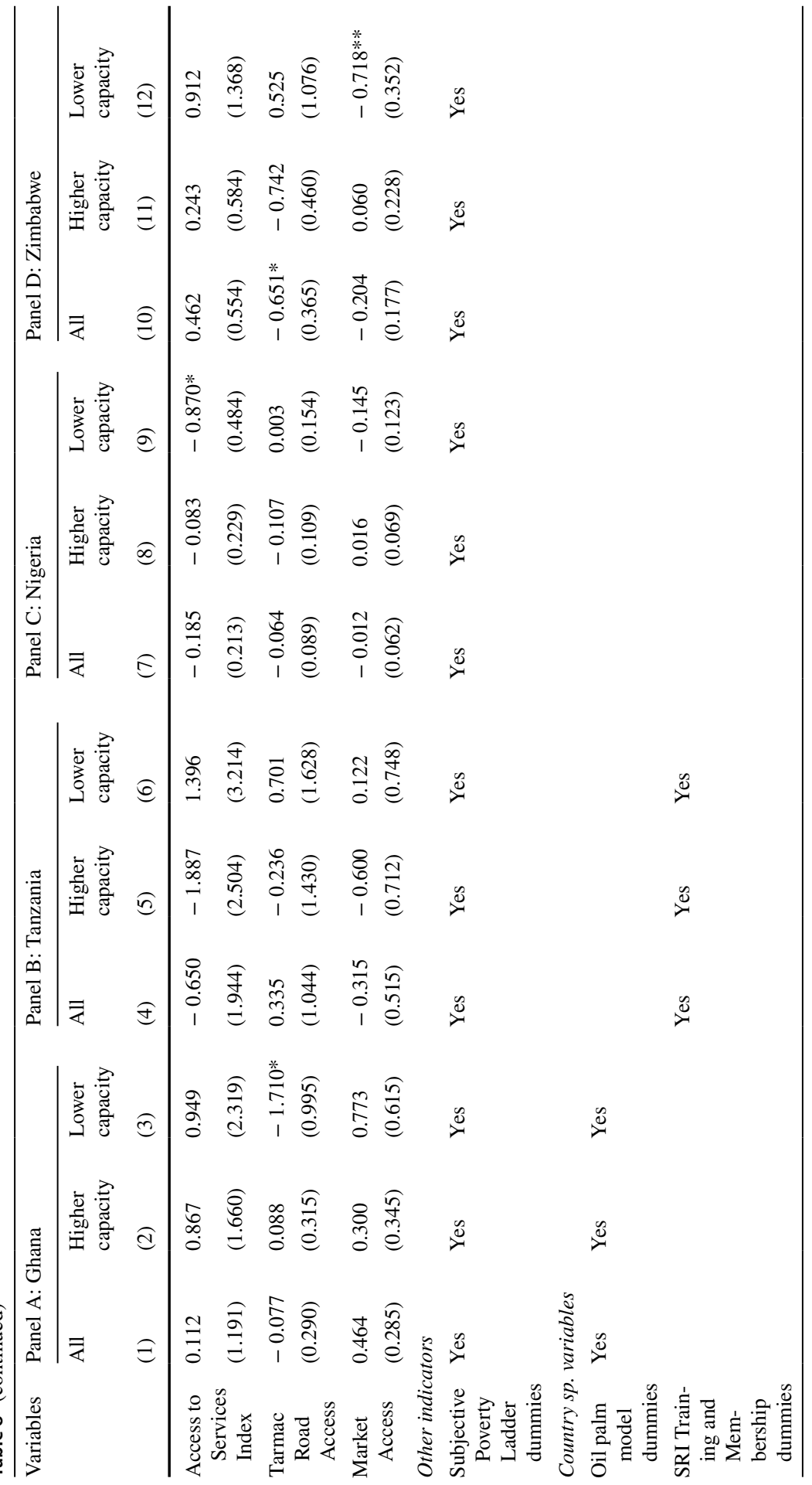




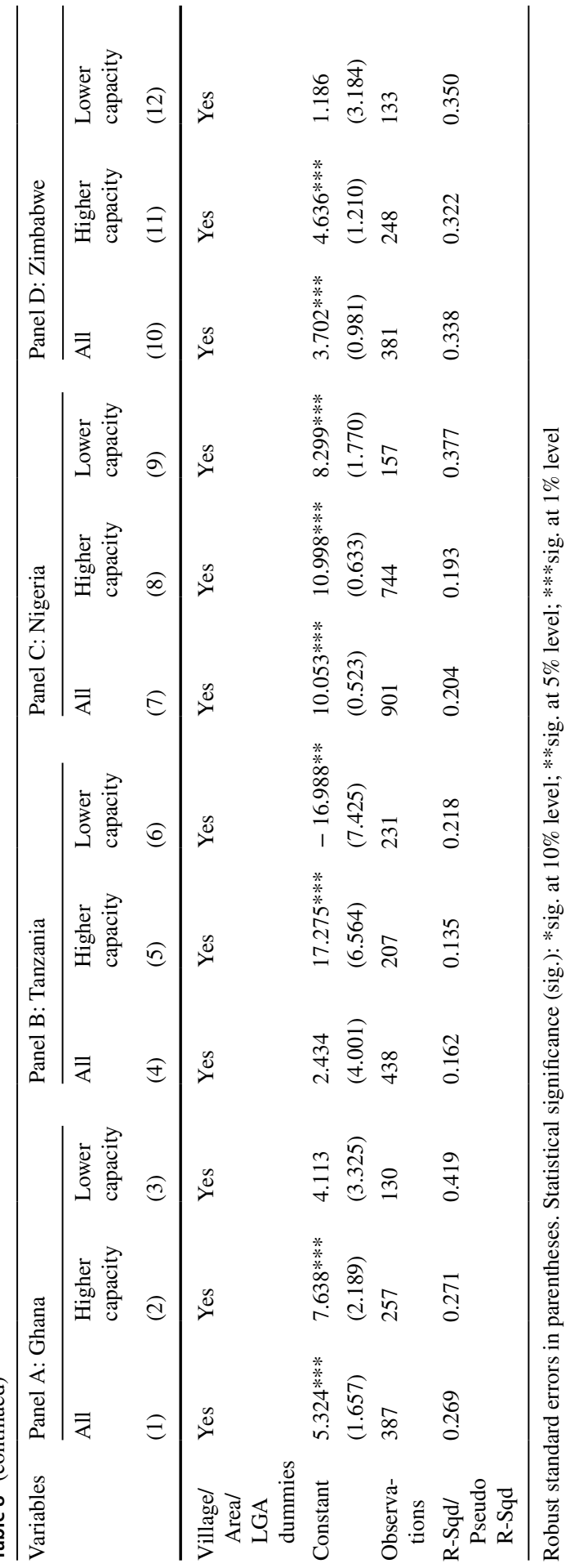




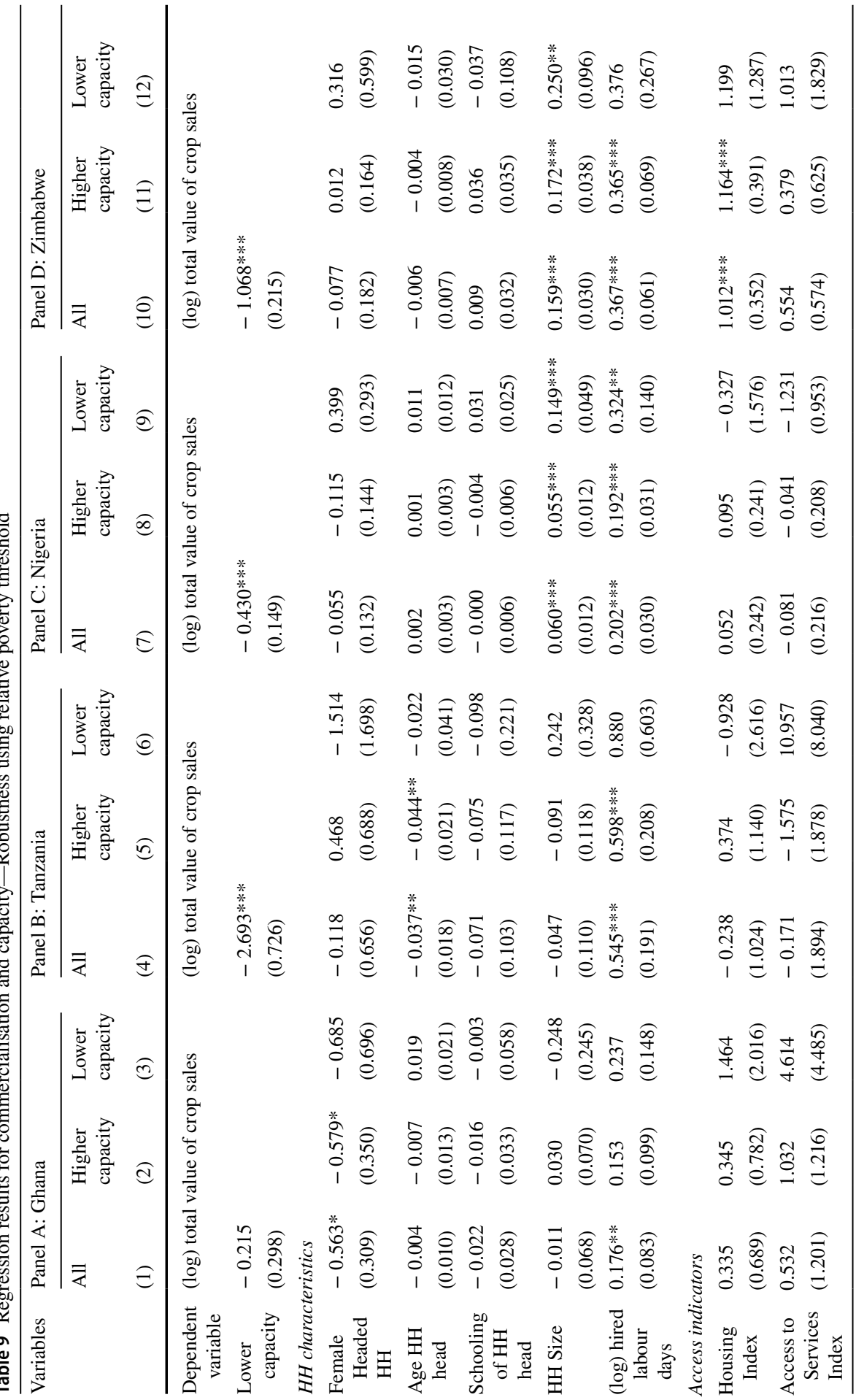




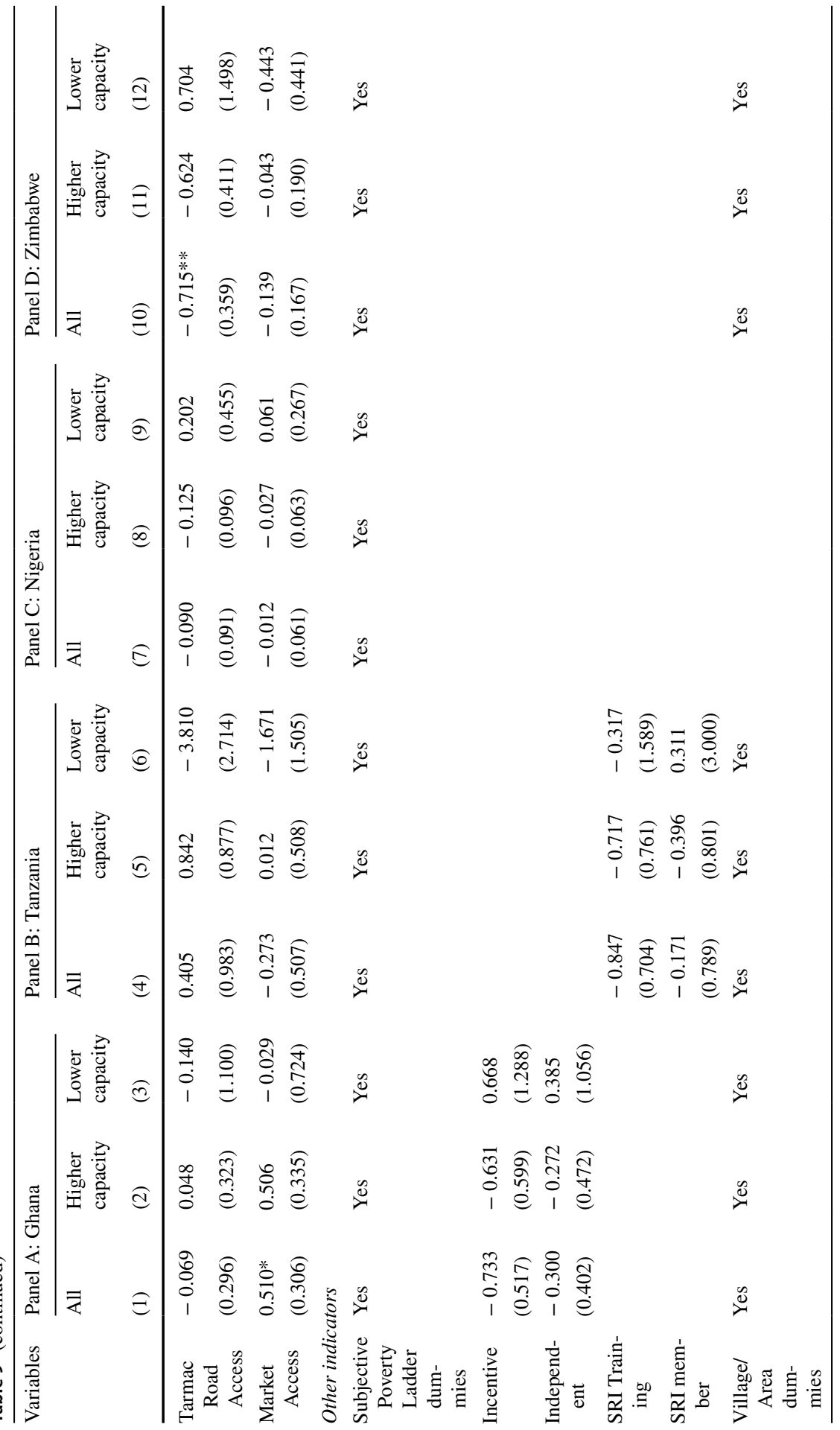




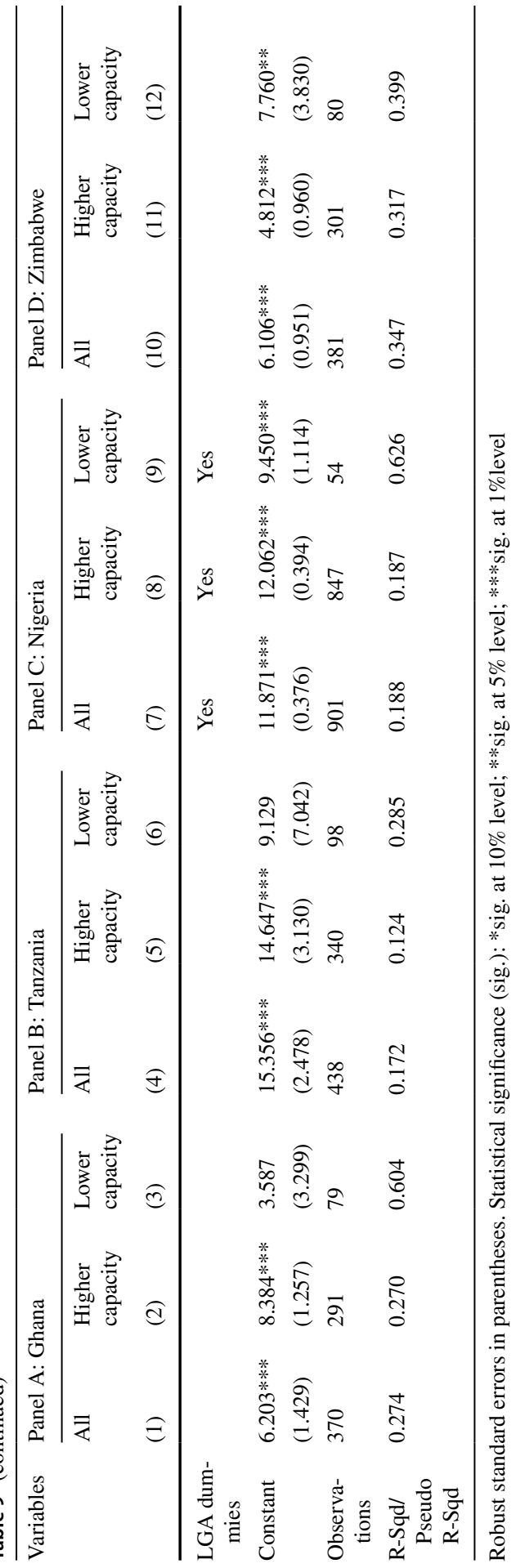

站。 
Table 10 Details of propensity score matching-lower capacity

\begin{tabular}{lllll}
\hline Variables & $(1)$ & $(2)$ & $(3)$ & $(4)$ \\
& Ghana & Tanzania & Nigeria & Zimbabwe \\
\hline Dependent variable & Lower capacity & Lower capacity & Lower capacity & Lower capacity \\
Female Headed HH & 0.442 & 0.110 & -0.093 & $0.827^{* *}$ \\
& $(0.280)$ & $(0.293)$ & $(0.354)$ & $(0.334)$ \\
Age HH head & 0.005 & 0.009 & 0.008 & $-0.018^{*}$ \\
& $(0.008)$ & $(0.007)$ & $(0.007)$ & $(0.011)$ \\
Schooling of HH head & -0.029 & $-0.093^{* *}$ & -0.002 & 0.012 \\
& $(0.026)$ & $(0.039)$ & $(0.020)$ & $(0.049)$ \\
HH Size & $0.190^{* * *}$ & 0.045 & -0.057 & $0.157^{* * *}$ \\
& $(0.055)$ & $(0.046)$ & $(0.036)$ & $(0.052)$ \\
(log) hired labour days & $-0.222^{* * *}$ & & 0.010 & $-0.326^{* * *}$ \\
& $(0.076)$ & & $(0.074)$ & $(0.090)$ \\
Housing Index & $1.195^{* *}$ & & 0.781 & $-2.118^{* * *}$ \\
Access to Services Index & $-5.138^{* * *}$ & & $(0.690)$ & $(0.550)$ \\
& $(1.009)$ & & -0.505 & -0.430 \\
Tarmac Road Access & -0.154 & 0.136 & $(0.623)$ & $(1.048)$ \\
Market Access & $(0.237)$ & $(0.416)$ & $-0.550^{* *}$ & 0.421 \\
Subjective poverty & $0.392^{*}$ & $-0.448^{* *}$ & $(0.219)$ & $(0.784)$ \\
Constant & $(0.224)$ & $(0.215)$ & -0.140 & $-0.645^{* *}$ \\
Observations & $-0.281^{* * *}$ & & $(0.190)$ & $(0.275)$ \\
\hline & $(0.090)$ & & $-0.456^{* * *}$ & $-0.392^{* * *}$ \\
& $2.001^{* *}$ & 0.176 & $(0.073)$ & $(0.075)$ \\
& $(0.865)$ & $(0.535)$ & 0.549 & $3.265^{* *}$ \\
& 465 & 441 & $(0.600)$ & $(1.292)$ \\
& & & 957 & 381 \\
\hline
\end{tabular}


Table 11 Results of covariate balancing test

\begin{tabular}{|c|c|c|c|c|c|c|c|}
\hline Variable & Sample & Treated & Control & $\%$ bias & bias & T-test & $\mathrm{p}>\mathrm{t}$ \\
\hline \multicolumn{8}{|l|}{ Ghana } \\
\hline \multirow[t]{2}{*}{ Female Headed HH } & Unmatched & 0.29231 & 0.22957 & 14.3 & & 1.34 & 0.180 \\
\hline & Matched & 0.29231 & 0.29231 & 0 & 100 & 0.00 & 1.000 \\
\hline \multirow[t]{2}{*}{ Age $\mathrm{HH}$ head } & Unmatched & 49.892 & 50.405 & -3.8 & & -0.35 & 0.723 \\
\hline & Matched & 49.892 & 51.338 & -10.9 & -182.3 & -0.92 & 0.357 \\
\hline \multirow[t]{2}{*}{ Schooling of $\mathrm{HH}$ head } & Unmatched & 5.7923 & 7.1868 & -29.3 & & -2.72 & 0.007 \\
\hline & Matched & 5.7923 & 6.1692 & -7.9 & 73 & -0.64 & 0.524 \\
\hline \multirow[t]{2}{*}{ HH Size } & Unmatched & 4.6385 & 3.8093 & 40.2 & & 3.75 & 0.000 \\
\hline & Matched & 4.6385 & 4.3154 & 15.7 & 61 & 1.22 & 0.222 \\
\hline \multirow[t]{2}{*}{$(\log )$ hired labour days } & Unmatched & 1.0718 & 1.6693 & -39.3 & & -3.58 & 0.000 \\
\hline & Matched & 1.0718 & 1.125 & -3.5 & 91.1 & -0.3 & 0.765 \\
\hline \multirow[t]{2}{*}{ Housing Index } & Unmatched & 0.68754 & 0.71995 & -16.7 & & -1.57 & 0.116 \\
\hline & Matched & 0.68754 & 0.71531 & -14.3 & 14.3 & -1.16 & 0.248 \\
\hline \multirow[t]{2}{*}{ Access to Services Index } & Unmatched & 0.56974 & 0.65091 & -67.6 & & -6.33 & 0.000 \\
\hline & Matched & 0.56974 & 0.60452 & -29 & 57.1 & -2.43 & 0.016 \\
\hline \multirow[t]{2}{*}{ Tarmac Road Access } & Unmatched & 0.29231 & 0.40856 & -24.5 & & -2.25 & 0.025 \\
\hline & Matched & 0.29231 & 0.36154 & -14.6 & 40.4 & -1.19 & 0.236 \\
\hline \multirow[t]{2}{*}{ Market Access } & Unmatched & 0.54615 & 0.48638 & 11.9 & & 1.11 & 0.268 \\
\hline & Matched & 0.54615 & 0.53846 & 1.5 & 87.1 & 0.12 & 0.901 \\
\hline \multirow[t]{2}{*}{ Subjective Poverty } & Unmatched & 3.9308 & 4.5097 & -45.5 & & -4.23 & 0.000 \\
\hline & Matched & 3.9308 & 4.0462 & -9.1 & 80.1 & -0.75 & 0.453 \\
\hline \multirow[t]{2}{*}{ Pseudo R2 } & Unmatched & 0.174 & & & & & \\
\hline & Matched & 0.034 & & & & & \\
\hline \multirow[t]{2}{*}{ LR Chi2 } & Unmatched & $85.78 * * *$ & & & & & \\
\hline & Matched & 12.32 & & & & & \\
\hline \multicolumn{8}{|l|}{ Tanzania } \\
\hline \multirow[t]{2}{*}{ Female Headed HH } & Unmatched & 0.15021 & 0.125 & 7.3 & & 0.76 & 0.445 \\
\hline & Matched & 0.11538 & 0.125 & -2.8 & 61.9 & -0.3 & 0.764 \\
\hline \multirow[t]{2}{*}{ Age $\mathrm{HH}$ head } & Unmatched & 46.292 & 43.625 & 19.6 & & 2.04 & 0.042 \\
\hline & Matched & 44.683 & 43.625 & 7.8 & 60.3 & 0.83 & 0.407 \\
\hline \multirow[t]{2}{*}{ Schooling of HH head } & Unmatched & 5.9528 & 6.7404 & -29.5 & & -3.07 & 0.002 \\
\hline & Matched & 6.524 & 6.7404 & -8.1 & 72.5 & -0.9 & 0.367 \\
\hline \multirow[t]{2}{*}{ HH Size } & Unmatched & 5.0386 & 4.774 & 12.1 & & 1.27 & 0.206 \\
\hline & Matched & 5 & 4.774 & 10.3 & 14.6 & 1.05 & 0.296 \\
\hline \multirow[t]{2}{*}{ (log) hired labour days } & Unmatched & & & & & & \\
\hline & Matched & & & & & & \\
\hline \multirow[t]{2}{*}{ Housing Index } & Unmatched & & & & & & \\
\hline & Matched & & & & & & \\
\hline \multirow[t]{2}{*}{ Access to Services Index } & Unmatched & & & & & & \\
\hline & Matched & & & & & & \\
\hline \multirow[t]{2}{*}{ Tarmac Road Access } & Unmatched & 0.06009 & 0.05769 & 1 & & 0.11 & 0.915 \\
\hline & Matched & 0.05769 & 0.05769 & 0 & 100 & 0 & 1 \\
\hline
\end{tabular}


Table 11 (continued)

\begin{tabular}{|c|c|c|c|c|c|c|c|}
\hline Variable & Sample & Treated & Control & \%bias & bias & T-test & $\mathrm{p}>\mathrm{t}$ \\
\hline \multirow[t]{2}{*}{ Market Access } & Unmatched & 0.25322 & 0.33654 & -18.3 & & -1.92 & 0.055 \\
\hline & Matched & 0.27404 & 0.33654 & -13.7 & 25 & -1.38 & 0.167 \\
\hline \multirow[t]{2}{*}{ Subjective Poverty } & Unmatched & 0.15021 & 0.125 & 7.3 & & 0.76 & 0.445 \\
\hline & Matched & 0.11538 & 0.125 & -2.8 & 61.9 & -0.3 & 0.764 \\
\hline \multirow[t]{2}{*}{ Pseudo R2 } & Unmatched & 0.026 & & & & & \\
\hline & Matched & 0.175 & & & & & \\
\hline \multirow[t]{2}{*}{ LR Chi2 } & Unmatched & $16.080^{* *}$ & & & & & \\
\hline & Matched & 0.008 & & & & & \\
\hline \multicolumn{8}{|l|}{ Nigeria } \\
\hline \multirow[t]{2}{*}{ Female Headed HH } & Unmatched & 0.07643 & 0.06317 & 5.2 & & 0.61 & 0.542 \\
\hline & Matched & 0.07643 & 0.09554 & -7.5 & -44.1 & -0.6 & 0.547 \\
\hline \multirow[t]{2}{*}{ Age HH head } & Unmatched & 45.898 & 44.985 & 6.8 & & 0.77 & 0.439 \\
\hline & Matched & 45.898 & 46.599 & -5.2 & 23.2 & -0.46 & 0.648 \\
\hline \multirow[t]{2}{*}{ Schooling of $\mathrm{HH}$ head } & Unmatched & 6.4904 & 7.1586 & -13.7 & & -1.49 & 0.137 \\
\hline & Matched & 6.4904 & 6.6561 & -3.4 & 75.2 & -0.31 & 0.757 \\
\hline \multirow[t]{2}{*}{ HH Size } & Unmatched & 5.3567 & 5.8306 & -18.4 & & -1.96 & 0.05 \\
\hline & Matched & 5.3567 & 5.4522 & -3.7 & 79.8 & -0.33 & 0.739 \\
\hline \multirow[t]{2}{*}{ (log) hired labour days } & Unmatched & 2.2431 & 2.2012 & 3.6 & & 0.4 & 0.69 \\
\hline & Matched & 2.2431 & 2.2579 & -1.3 & 64.8 & -0.11 & 0.91 \\
\hline \multirow[t]{2}{*}{ Housing Index } & Unmatched & 0.6793 & 0.69049 & -7.9 & & -0.88 & 0.38 \\
\hline & Matched & 0.6793 & 0.67619 & 2.2 & 72.2 & 0.19 & 0.848 \\
\hline \multirow[t]{2}{*}{ Access to Services Index } & Unmatched & 0.41738 & 0.46766 & -29 & & -3.33 & 0.001 \\
\hline & Matched & 0.41738 & 0.42106 & -2.1 & 92.7 & -0.18 & 0.854 \\
\hline \multirow[t]{2}{*}{ Tarmac Road Access } & Unmatched & 0.70701 & 0.85484 & -36.2 & & -4.52 & 0.000 \\
\hline & Matched & 0.70701 & 0.68153 & 6.2 & 82.8 & 0.49 & 0.625 \\
\hline \multirow[t]{2}{*}{ Market Access } & Unmatched & 0.43312 & 0.45833 & -5.1 & & -0.58 & 0.565 \\
\hline & Matched & 0.43312 & 0.32484 & 21.7 & -329.5 & 1.98 & 0.048 \\
\hline \multirow[t]{2}{*}{ Subjective Poverty } & Unmatched & 3.8599 & 4.8253 & -67.7 & & -7.63 & 0.000 \\
\hline & Matched & 3.8599 & 3.8726 & -0.9 & 98.7 & -0.08 & 0.934 \\
\hline \multirow[t]{2}{*}{ Pseudo R2 } & Unmatched & 0.087 & & & & & \\
\hline & Matched & 0.012 & & & & & \\
\hline \multirow[t]{2}{*}{ LR Chi2 } & Unmatched & $72.84 * * *$ & & & & & \\
\hline & Matched & 5.10 & & & & & \\
\hline \multicolumn{8}{|l|}{ Zimbabwe } \\
\hline \multirow[t]{2}{*}{ Female Headed HH } & Unmatched & 0.24812 & 0.14919 & 24.9 & 2.39 & 0.017 & 0.24812 \\
\hline & Matched & 0.24812 & 0.21805 & 7.6 & 69.6 & 0.58 & 0.24812 \\
\hline \multirow[t]{2}{*}{ Age $\mathrm{HH}$ head } & Unmatched & 49.346 & 50.629 & -9.8 & -0.9 & 0.369 & 49.346 \\
\hline & Matched & 49.346 & 48.466 & 6.7 & 31.4 & 0.54 & 49.346 \\
\hline \multirow[t]{2}{*}{ Schooling of $\mathrm{HH}$ head } & Unmatched & 8.406 & 8.9556 & -19.4 & -1.78 & 0.076 & 8.406 \\
\hline & Matched & 8.406 & 8.5188 & -4 & 79.5 & -0.31 & 8.406 \\
\hline \multirow[t]{2}{*}{ HH Size } & Unmatched & 6.4436 & 5.7339 & 28.4 & 2.7 & 0.007 & 6.4436 \\
\hline & Matched & 6.4436 & 6.2481 & 7.8 & 72.5 & 0.61 & 6.4436 \\
\hline
\end{tabular}


Table 11 (continued)

\begin{tabular}{|c|c|c|c|c|c|c|c|}
\hline Variable & Sample & Treated & Control & \%bias & bias & T-test & $\mathrm{p}>\mathrm{t}$ \\
\hline \multirow[t]{2}{*}{ (log) hired labour days } & Unmatched & 1.5494 & 2.4172 & -62.6 & -5.83 & 0 & 1.5494 \\
\hline & Matched & 1.5494 & 1.9115 & -26.1 & 58.3 & -2.09 & 1.5494 \\
\hline \multirow[t]{2}{*}{ Housing Index } & Unmatched & 0.63546 & 0.75922 & -54.4 & -5.3 & 0 & 0.63546 \\
\hline & Matched & 0.63546 & 0.70429 & -30.3 & 44.4 & -2.33 & 0.63546 \\
\hline \multirow[t]{2}{*}{ Access to Services Index } & Unmatched & 0.39286 & 0.42143 & -22.4 & -2.11 & 0.035 & 0.39286 \\
\hline & Matched & 0.39286 & 0.40857 & -12.3 & 45 & -1.02 & 0.39286 \\
\hline \multirow[t]{2}{*}{ Tarmac Road Access } & Unmatched & 0.97744 & 0.96371 & 8.1 & 0.73 & 0.466 & 0.97744 \\
\hline & Matched & 0.97744 & 0.96992 & 4.4 & 45.3 & 0.38 & 0.97744 \\
\hline \multirow[t]{2}{*}{ Market Access } & Unmatched & 0.62406 & 0.67742 & -11.2 & -1.05 & 0.296 & 0.62406 \\
\hline & Matched & 0.62406 & 0.65414 & -6.3 & 43.6 & -0.51 & 0.62406 \\
\hline \multirow[t]{2}{*}{ Subjective Poverty } & Unmatched & 4.1278 & 5.4073 & -70.6 & -6.6 & 0 & 4.1278 \\
\hline & Matched & 4.1278 & 4.594 & -25.7 & 2.39 & -2.25 & 4.1278 \\
\hline \multirow[t]{2}{*}{ Pseudo R2 } & Unmatched & 0.204 & & & & 0.017 & \\
\hline & Matched & 0.050 & & & & & \\
\hline \multirow[t]{2}{*}{ LR Chi2 } & Unmatched & $100.56^{* * *}$ & & & & & \\
\hline & Matched & 18.54 & & & & & \\
\hline
\end{tabular}

Logit estimation of propensity score. Statistical significance (sig.): *sig. at $10 \%$ level; **sig. at $5 \%$ level; $* * *$ sig. at $1 \%$ level

Using a nearest neighbour matching and imposing a common support condition. \% Bias is calculated as $100 * \frac{\left(X_{T}-X_{C}\right)}{\sqrt{0.5\left(V_{T}(X)+V_{C}(X)\right)}}$. T-test is the mean test the for baseline period. Pseudo R2 of the propensity score on all the variables both before and after matching. And corresponding likelihood-ratio test of the joint insignificance of all the regressors (before and after matching). Statistical significance (sig.): *sig. at $10 \%$ level; **sig. at $5 \%$ level; ***sig. at $1 \%$ level 

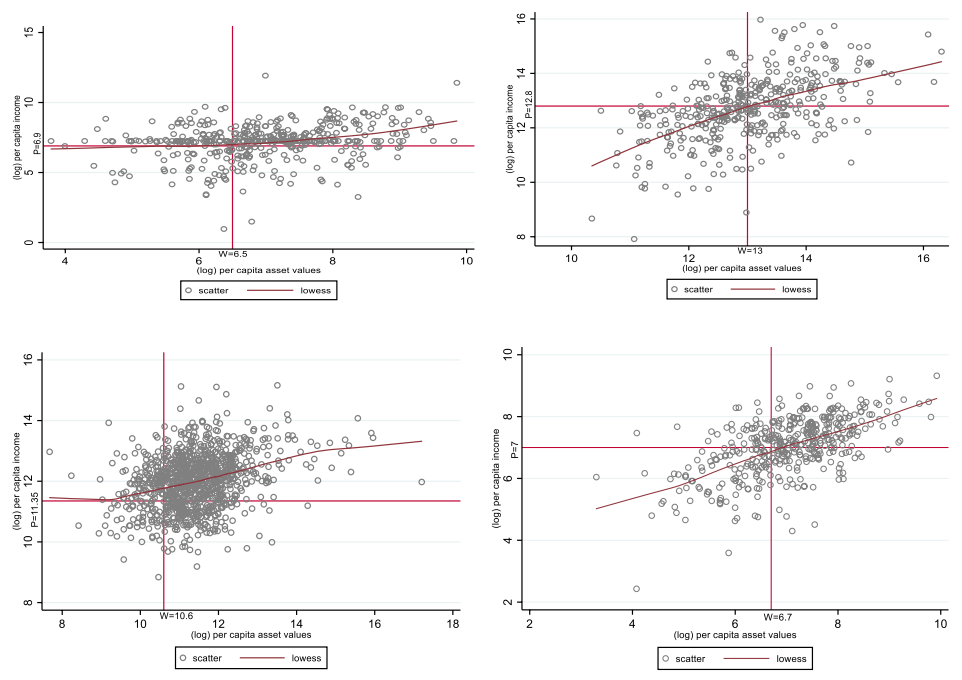

Nigeria

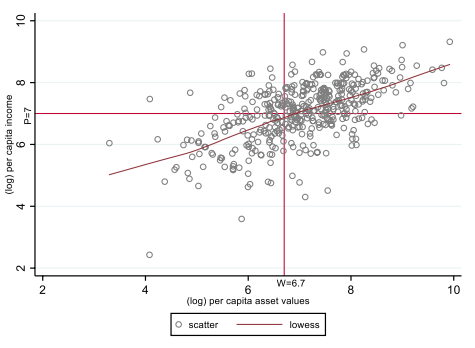

Zimbabwe

Note: Locally weighted regression of $(\log )$ per capita asset values and $(\log )$ per capita adult equivalent incomes - both in local currency units. Assets indude hoe, spade, axe, sidkle, shears, knife, sprayer and water pump, mattress, cooking stove, radio, television, mobile phone, fridge, bicyde, motorcyde \& car/trudk, land, and livestodk.

Fig. 3 Identifying asset thresholds (W) for Ghana, Tanzania, Nigeria and Zimbabwe. Note Locally weighted regression of $(\log )$ per capita asset values and $(\log )$ per capita adult equivalent incomes-both in local currency units. Assets include hoe, spade, axe, sickle, shears, knife, sprayer and water pump, mattress, cooking stove, radio, television, mobile phone, fridge, bicycle, motorcycle and car/truck, land, and livestock

Supplementary Information The online version contains supplementary material available at https://doi. org/10.1057/s41287-021-00414-z.

Acknowledgements Financial support from the Foreign, Commonwealth \& Development Office (FCDO), UK is gratefully acknowledged. The authors would like to thank country partners and members of the Agricultural Policy Research in Africa (APRA) consortium for their invaluable support in implementing the study—especially Fred Dzanku, Louis Hodey, Aida Isinika, Gideon Boniface, Adebayo Aromolaran, Milu Muyanga, Vine Mutyasira, Chrispen Sukume, among others; we also acknowledge advice from Andy McKay, Ricardo Sabates, Kalle Hirvonen, and Thom Jayne. Any remaining errors are entirely ours.

Author Contribution AS: Conceptualization, Methodology, Data Collection, Data curation, Formal analysis, Validation, Project administration, Writing_original draft, review and editing; R-SW: Conceptualization, Methodology, Investigation, Project administration, Writing — original draft, review and editing; JT: Funding acquisition, Project administration, Writing—review.

\section{Declaration}

Conflict of interest On behalf of all authors, the corresponding author states that there is no conflict of interest.

Open Access This article is licensed under a Creative Commons Attribution 4.0 International License, which permits use, sharing, adaptation, distribution and reproduction in any medium or format, as long as you give appropriate credit to the original author(s) and the source, provide a link to the Creative Commons licence, and indicate if changes were made. The images or other third party material in this article are included in the article's Creative Commons licence, unless indicated otherwise in a credit line to the 
material. If material is not included in the article's Creative Commons licence and your intended use is not permitted by statutory regulation or exceeds the permitted use, you will need to obtain permission directly from the copyright holder. To view a copy of this licence, visit http://creativecommons.org/licen ses/by/4.0/.

\section{References}

Arslan, A., D.E. Tschirley, and E. Egger. 2020. Rural Youth Welfare along the Rural-urban Gradient: An Empirical Analysis Across the Developing World. The Journal of Development Studies. https://doi. org/10.1080/00220388.2020.1808197.

Appiah-Kubi, Kojo, Abena D. Oduro, and Bernardin Senadza. 2008. Understanding poverty in Ghana: Risk and vulnerability. In Ernest Aryeetey and Ravi Kanbur (eds.), The Economy of Ghana: Analytical Perspectives on Stability, Growth and Poverty. James Currey \& Woeli Publishing Services, Rochester.

Azam, Md Shafiul, and Katsushi S. Imai. 2009. Vulnerability and poverty in Bangladesh. Chronic poverty research Centre working paper (141).

Bachewe, F.N., G. Berhane, B. Minten, and A.S. Taffesse. 2018. Agricultural transformation in Africa? Assessing the evidence in Ethiopia. World Development 105: 286-298.

Barrett, Christopher B. 2008. Smallholder market participation: Concepts and evidence from eastern and southern Africa. Food Policy 33 (4): 299-317.

Barrett, Christopher B., and Mark A. Constas. 2014. Toward a theory of resilience for international development applications. Proceedings of the National Academy of Sciences 111 (40): 14625-14630. https://doi.org/10.1073/pnas.1320880111.

Bellemare, M.F. 2012. As you sow, so shall you reap: The welfare impacts of contract farming. World Development 40 (7): 1418-1434.

Birner, R., and D. Resnick. 2010. The political economy of policies for smallholder agriculture. World Development 38 (10): 1442-1452.

Burke, W.J., T.S. Jayne, and N.J. Sitko. 2020. Do medium-scale farms improve market access conditions for Zambian smallholders? Journal of Agricultural Economics 71 (2): 517-533.

Calvo, Cesar, and Stefan Dercon. 2013. Vulnerability to individual and aggregate poverty. Social Choice and Welfare 41 (4): 721-740.

Cahyadi, E.R., and H. Waibel. 2016. Contract farming and vulnerability to poverty among oil palm smallholders in Indonesia. The Journal of Development Studies 52 (5): 681-695.

Caliendo, M., and S. Kopeinig. 2008. Some practical guidance for the implementation of propensity score matching. Journal of Economic Surveys 22 (1): 31-72.

Carletto, Calogero, Paul Corral, and Anita Guelfi. 2017. Agricultural commercialization and nutrition revisited: Empirical evidence from three African countries. Food Policy 67: 106-118.

Carreras, M., Sumberg, J. and Saha, A., 2020. Work and Rural Livelihoods: The Micro Dynamics of Africa's 'Youth Employment Crisis'. The European Journal of Development Research, pp. 1-29.

Carter, Michael R., and Christopher B. Barrett. 2006. The economics of poverty traps and persistent poverty: An asset-based approach. The Journal of Development Studies 42 (2): 178-199.

Cazzuffi, C., McKay, A. and Perge, E., 2020. The impact of agricultural commercialisation on household welfare in rural Vietnam. Food Policy, p.101811.

Chaudhuri, S., and G. Datt. 2001. Assessing household vulnerability to poverty: a methodology and estimates for the Philippines. Singapore: World Bank.

Chaudhuri, Shubham. 2003. Assessing vulnerability to poverty: Concepts, empirical methods and illustrative examples.

Chaudhuri, Shubham, Jyotsna Jalan, and Asep Suryahadi. 2002. "Assessing household vulnerability to poverty from cross-sectional data: A methodology and estimates from Indonesia."

Chaves, M., T. Macintyre, G. Verschoor, and A.E. Wals. 2018. Radical ruralities in practice: Negotiating buen vivir in a Colombian network of sustainability. Journal of Rural Studies 59: 153-162.

Chirwa, E., R. Sabates-Wheeler, and A. Saha. 2018. Agricultural Policy Research in Africa (APRA) indicators report. 
Christiaensen, Luc J., and Kalanidhi Subbarao. 2005. Towards an understanding of household vulnerability in rural Kenya. Journal of African Economies 14 (4): 520-558.

Cissé, Jennifer Denno, and Christopher B. Barrett. 2018. Estimating development resilience: A conditional moments-based approach. Journal of Development Economics 135: 272-284.

Davis, Peter, and Bob Baulch. 2011. Parallel realities: Exploring poverty dynamics using mixed methods in rural Bangladesh. The Journal of Development Studies 47 (1): 118-142.

Deaton, A. and Zaidi, S. 2002. Guidelines for Constructing Consumption Aggregates for Welfare Analysis. LSMS Working Paper No. 135. World Bank, Washington, DC.

Dillon, B. and Barrett, C.B., 2014. Agricultural factor markets in Sub-Saharan Africa: An updated view with formal tests for market failure. The World Bank.

Dolislager, M., T. Reardon, A. Arslan, L. Fox, S. Liverpool-Tasie, C. Sauer, and D.L. Tschirley. 2020. Youth and adult agrifood system employment in developing regions: Rural (Peri-urban to Hinterland) vs Urban. The Journal of Development Studies. https://doi.org/10.1080/00220388.2020.18081 98.

Dorward, Andrew. 2009. Integrating contested aspirations, processes and policy: Development as hanging in, stepping up and stepping out. Development Policy Review 27 (2): 131-146.

Dorward, A., S. Anderson, Y.N. Bernal, E.S. Vera, J. Rushton, J. Pattison, and R. Paz. 2009. Hanging in, stepping up and stepping out: Livelihood aspirations and strategies of the poor. Development in Practice 19 (2): 240-247.

Dzanku, F.M., Asante, K.T., Quarmine, W. and Hodey, L.S., 2020. Smallholder farmers' choice of oil palm commercialisation model and household welfare in South-western Ghana. Working Paper 43. Brighton: Future Agricultures Consortium

Filmer, Deon, and Kinnon Scott. 2008. Assessing asset indices. Singapore: The World Bank.

Foster, James, Joel Greer, and Erik Thorbecke. 1984. "A class of decomposable poverty measures." Econometrica Journal of the Econometric Society,761-766.

Govereh, J., and T.S. Jayne. 2003. Cash cropping and food crop productivity: synergies or trade-offs? Agricultural Economics 28 (1): 39-50.

Günther, I., and K. Harrtgen. 2009. Estimating households vulnerability to idiosyncratic and covariate shocks: A novel method applied in Madagaskar. World Development 37 (7): 1222-1234. https://doi. org/10.1016/j.worlddev.2008.11.006v.

GSS. 2018. Ghana living standards survey round 7 (GLSS 7): Poverty trends in Ghana (2005-2017). Retrieved on 11/17/2018 from Ghana Statistical Service, Accra.

Hall, R., I. Scoones, and D. Tsikata. 2017. Plantations, outgrowers and commercial farming in Africa: Agricultural commercialisation and implications for agrarian change. The Journal of Peasant Studies 44 (3): 515-537.

Hernández, R., T. Reardon, and J. Berdegué. 2007. Supermarkets, wholesalers, and tomato growers in Guatemala. Agricultural Economics 36 (3): 281-290.

Jamal, Haroon. 2009. "Assessing vulnerability to poverty: evidence from pakistan."

Josphat, Mushongah, and Ian Scoones. 2012. Livelihood change in rural Zimbabwe over 20 years. Journal of Development Studies 48 (9): 1241-1257.

Leavy, Jennifer, and Colin Poulton. 2007. Commercialisations in agriculture. Ethiopian Journal of Economics 16 (1): 1-37.

Ligon, Ethan, and Laura Schechter. 2003. Measuring vulnerability. The Economic Journal 113 (486): C95-C102.

Matthys, M.L., S. Acharya, and S. Khatri. 2021. "Before cardamom, we used to face hardship": Analyzing agricultural commercialization effects in Nepal through a local concept of the Good Life. World Development 141: 105410.

Muricho, Geoffrey, Damiano Manda, Fredrick Sule, and Menale Kassie. 2017. Smallholder agricultural commercialization and poverty: empirical evidence of panel data from Kenya.

Mutabazi, K., Wiggins, S., and Mdoe, N., 2013. Commercialisation of African smallholder farming. The case of smallholder farmers in central Tanzania.

Muyanga, M., Aromolaran, A., Jayne, T., Liverpool-Tasie, S., Awokuse, T., and Adelaja, A., 2019. Changing farm structure and agricultural commercialisation in Nigeria.

Michelson, H.C. 2013. Small farmers, NGOs, and a Walmart world: Welfare effects of supermarkets operating in Nicaragua. American Journal of Agricultural Economics 95 (3): 628-649. https://doi. org/10.1093/ajae/aas139.

Muriithi, Beatrice W., and Julia Anna Matz. 2015. Welfare effects of vegetable commercialization: Evidence from smallholder producers in Kenya. Food Policy 50: 80-91. 
Nakano, Y., Y. Tanaka, and K. Otsuka. 2018. Impact of training on the intensification of rice farming: Evidence from rainfed areas in Tanzania. Agricultural Economics 49 (2): 193-202.

Ogutu, S.O., and M. Qaim. 2019. Commercialization of the small farm sector and multidimensional poverty. World Development 114: 281-293.

Ogutu, S.O., T. Gödecke, and M. Qaim. 2020. Agricultural commercialisation and nutrition in smallholder farm households. Journal of Agricultural Economics 71 (2): 534-555.

Phadera, Lokendra, Hope Michelson, Alex Winter-Nelson, and Peter Goldsmith. 2019. Do asset transfers build household resilience? Journal of Development Economics 138: 205-227.

Pingali, P.L., and M.W. Rosegrant. 1995. Agricultural commercialization and diversification: Processes and policies. Food Policy 20 (3): 171-185.

Poulton, Colin. 2017. "What is Agricultural Commercialisation, Why is it Important, and how do we Measure it?".

Pritchett, Lant, Asep Suryahadi, and Sudarno Sumarto. 2000. Quantifying vulnerability to poverty: A proposed measure, applied to Indonesia. World Bank Publications.

Rao, E.J., and M. Qaim. 2011. Supermarkets, farm household income, and poverty: Insights from Kenya. World Development 39 (5): 784-796.

Rahut, Dil Bahadur, Iván Velásquez Castellanos, and Pravakar Sahoo. 2010. Commercialization of agriculture in the Himalayas.

Rhebergen, T., S. Zingore, K.E. Giller, C.A. Frimpong, K. Acheampong, F.T. Ohipeni, E.K. Panyin, V. Zutah, and T. Fairhurst. 2020. Closing yield gaps in oil palm production systems in Ghana through Best Management Practices. European Journal of Agronomy 115: 126011.

Rosenbaum, P., and D. Rubin. 1983. The central role of the propensity score in observational studies for causal effects. Biometrika 70: 41-55.

Sadoulet, E., and A. De Janvry. 1995. Quantitative development policy analysis, vol. 5. Baltimore: Johns Hopkins University Press.

Scoones, I., B. Mavedzenge, F. Murimbarimba, and C. Sukume. 2018. Tobacco, contract farming, and agrarian change in Zimbabwe. Journal of Agrarian Change 18 (1): 22-42.

Scoones, I., N. Marongwe, B. Mavedzenge, F. Murimbarimba, F. Mahenehene and C. Sukume. 2010. Zimbabwe's Land Reform: Myths and Realities. Oxford: James Currey; Harare: Weaver Press; Johannesburg: Jacana.

Tipraqsa, Prasnee, and Pepijn Schreinemachers. 2009. Agricultural commercialization of Karen Hill tribes in northern Thailand. Agricultural Economics 40 (1): 43-53.

Tripathi, R.S., R. Singh, and S. Singh. 2005. Contract farming in potato reduction: An alternative for managing risks and uncertainty. Agricultural Economics Research Review 18: 47-60.

Von Braun, Joachim, and Eileen T. Kennedy. 1994. Agricultural commercialization, economic development, and nutrition: Washington, D.C.: Published for the International Food Policy Research Institute by Johns Hopkins University Press

Yaro, J.A., J.K. Teye, and G.D. Torvikey. 2017. Agricultural commercialisation models, agrarian dynamics and local development in Ghana. The Journal of Peasant Studies 44 (3): 538-554.

Zezza, A., P. Winters, B. Davis, G. Carletto, K. Covarrubias, L. Tasciotti, and E. Quiñones. 2011. Rural household access to assets and markets: A cross-country comparison. The European Journal of Development Research 23 (4): 569-597.

Ward, Patrick S. 2016. Transient poverty, poverty dynamics, and vulnerability to poverty: An empirical analysis using a balanced panel from rural China. World Development 78: 541-553.

West, J.J., and R. Haug. 2017. The vulnerability and resilience of smallholder-inclusive agricultural investments in Tanzania. Journal of Eastern African Studies 11 (4): 670-691.

World Bank. 2014. Introduction to Poverty Analysis. World Bank Group, Washington, DC. http://docum ents.worldbank.org/curated/en/775871468331250546/Introduction-to-poverty-analysis.

World Bank. 2015. Tanzania - Mainland poverty assessment (Vol. 2): Main report (English). Washington, D.C.: World Bank Group.

World Bank. 2016. Poverty Reduction in Nigeria in the Last Decade. Washington, DC. World Bank Group. https://openknowledge.worldbank.org/handle/10986/25825 License: CC BY 3.0 IGO.

Publisher's Note Springer Nature remains neutral with regard to jurisdictional claims in published maps and institutional affiliations. 